$r_{e}$ ALA

I. Estudios 



\title{
Los orígenes de la municipalización de servicios. El industrialismo público inglés (Municipal Trading) y la Sociedad Fabiana'
}

\author{
Nuria Magaldi \\ Profesora Ayudante Doctora de Derecho Administrativo \\ Universidad de Córdoba \\ nmagaldi@uco.es
}

Recibido: 4 de julio de 2011

Aceptado: 24 de octubre de 2011

\begin{abstract}
Resumen
A lo largo del siglo XIX hizo su aparición en Inglaterra un fenómeno nuevo, conocido como municipalización de servicios o municipal trading, en virtud del cual los municipios ingleses fueron asumiendo progresivamente la prestación de diversos servicios que habían devenido esenciales en las ciudades, como consecuencia de la Revolución Industrial y del intenso movimiento demográfico (campo-ciudad) que aquella había generado. En el marco teórico de este movimiento municipalizador destacó muy especialmente la aportación realizada por un grupo de pensadores e intelectuales aglutinados en torno a las figuras de Sydney y Beatrice Webb y Bernard Shaw (la Sociedad Fabiana) y que habrían de constituir el núcleo originario del laborismo británico.
\end{abstract}

Palabras clave Servicios públicos, municipalización, socialismo, sociedad fabiana, Inglaterra, Londres.

\section{The origins of the english municipal trading and the Fabian Society}

\begin{abstract}
Municipal trading appeared as a new phenomenon in England during the 19th century. As a consequence, English local authorities had to provide for new social needs that had become essential after the Industrial Revolution and the migrations from the countryside to the cities that followed. A group of intellectuals and thinkers who gathered around the figures of Sydney and Beatrice Webb and Bernard Shaw (the Fabian Society) played a capital role in building the theoretical framework of this movement. They became the original hard core of British Labor.
\end{abstract}

Key words

Public services, municipal trading, socialism, fabian society, England, London.

1 El presente trabajo es una reelaboración del capítulo II de mi Tesis doctoral, defendida el 17 de mayo de 2010 en la Universidad de Barcelona, con el título El tránsito del Estado liberal al Estado social a la luz de la municipalización de servicios públicos: los orígenes de la municipalización de servicios en España, ante un tribunal formado por los profesores Domenico Sorace, Luis Martín Rebollo y Manuel Rebollo Puig. Agradezco a los miembros del tribunal, y en especial a mi Directora de Tesis, la profesora Elisenda Malaret, los acertados comentarios que han permitido enriquecer el texto original.

El estudio se inserta en el seno del Grupo de Investigación SEJ-196, proyecto de investigación PER 2009-12146 del Ministerio de Ciencia e Innovación. 
“La mañana en que comenzaba este capítulo recibí dos publicaciones (...). Una de ellas se titulaba Municipal Ownership in Great Britain, por el Prof. Hugo Richard Meyer (324 páginas, Macmillan Company, 1906), y está dedicada a demostrar la tesis de que la municipalización en la Gran Bretaña ha sido un fracaso desde casi todos los puntos de vista. Por el contrario, el estudio monográfico por Frederic C. Howe, llamado Municipal Ownership in Great Britain -que es el resultado de una investigación especial hecha bajo los auspicios del Bureau of Labor de los Estados Unidos- está llena de datos y demostraciones para sostener la conclusión contraria (...)".

L. S. Rowe, El gobierno de la ciudad y sus problemas, Librería general Victoriano Suárez, Madrid, 1914.

\section{INTRODUCCIÓN}

En el actual contexto de crisis económica y política, los entes locales ocupan una parte importante del debate, siendo frecuentes las discusiones acerca de sus problemas financieros y de endeudamiento, su creciente incapacidad para asumir el coste de la prestación de determinados servicios a los ciudadanos o las siempre imprecisas y difíciles relaciones entre la libertad de empresa y la iniciativa económica local. Tales debates, que suelen plantearse en términos novedosos y recientes, son sin embargo muy similares a los que se plantearon, tanto en la Europa continental como en el mundo anglosajón, hace ya más de un siglo, a medida que los diversos países fueron transitando del Estado liberal de Derecho al Estado Social prestador de servicios. En efecto, quien esté familiarizado con el debate en materia de régimen local de los últimos años, quedará sorprendido ante la cercanía que algunos de los problemas actuales presentan con los que se plantearon hace prácticamente un siglo: las bondades y los defectos tanto de la competencia como del monopolio, el mantenimiento de este último sobre las infraestructuras instrumentales de los servicios en red, la (in)capacidad técnica de los administradores públicos para gestionar servicios de carácter económico y comercial, la posibilidad de obtener beneficios de dicha gestión o los límites de la intervención pública en la economía, entre otras.

Tales concomitancias entre dos momentos históricos tan aparentemente distintos entre sí obligan al actual estudioso del Derecho Administrativo, con frecuencia excesivamente condicionado por la sociedad del conocimiento y la innovación tecnológica y casi siempre prisionero de un proceso de especialización disciplinaria, a detenerse en el estudio de los contextos históricos y en el desarrollo evolutivo de las ideas $^{2}$. Y ello porque solo tomando conciencia del pasado y alcanzando un conocimiento adecuado del mismo nos será posible comprender el presente 3 .

2 A. Sandulli, Costruire lo Stato. La scienza del diritto administrativo in Italia (1800-1945), Biblioteca Quaderni Fiorentini per la storia del pensiero giuridico moderno n 84, Giuffrè, Milán, 2009, p. VI.

3 A. Sandulli, Costruire lo Stato..., cit., p. VIII y XII, para quien "el jurista debe ser historiador y el historiador, jurista”. En idéntico sentido también L. Mannori /B. Sordi, Storia del diritto amministrativo, Editori Laterza, Roma-Bari, 2001, p. VIII, para quienes, de este modo, la historia del Derecho Administrativo deja 
Este trabajo pretende evidenciar las innegables coincidencias existentes entre los debates actuales en materia de prestación de servicios públicos locales y los debates suscitados en la Inglaterra del siglo XIX en torno a los gobiernos locales, sus tareas y responsabilidades. No puede obviarse, en este sentido, el hecho de que Inglaterra fue el primer país en el que confluyeron y se enfrentaron las dos grandes corrientes del pensamiento político de la edad contemporánea. De una parte, el liberalismo, que había alcanzado el rango de corriente hegemónica a lo largo del siglo XVIII. De otra, el socialismo o, más precisamente para el caso inglés, la socialdemocracia, dado que en las Islas Británicas los movimientos hegemónicos de izquierdas (Fabian Society, primero, y Union Trades y laborismo, después), no cuestionaron seriamente las formas democráticas como sistema político y de gobierno más adecuado. Este mismo enfrentamiento, aunque con los papeles invertidos, es el que puede percibirse en la actualidad entre las corrientes socialdemócratas, principales valedoras hasta hoy de los Estados prestadores de servicios (Welfare State) y el pujante movimiento neo-liberal.

\section{PLANTEAMIENTO GENERAL}

Es bien conocido que el primer país en el que tuvo lugar la Revolución Industrial, a partir de la segunda mitad del siglo XVIII, con las consecuencias demográficas (aumento de la población y migraciones masivas del campo a la ciudad, con el consiguiente desarrollo urbano), económicas (producción en serie y desarrollo del capitalismo) y sociales (aparición del proletariado y de la denominada cuestión social) que aquella conllevaba, fue Inglaterra. Ello explica que fuera en este país el primer lugar en el que confluyeran las circunstancias oportunas y necesarias para que surgiera y se desarrollara el fenómeno de la municipalización de servicios y del industrialismo de los poderes públicos, particularmente de los poderes locales.

\footnotetext{
de identificarse con una "tranquilizadora introducción histórica a una inmutable parte general del Derecho Administrativo" para convertirse en historia "dinámica de las autoridades públicas y de sus modos de actuación, en historia de las formas del poder y de sus continuas e interrelacionadas transformaciones cíclicas".

Yo misma me he acogido a esta visión de la historia como parte esencial de la tarea del iuspublicista en mi trabajo N. Magaldi, Procura existencial, Estado de Derecho y Estado Social, Universidad del Externado, Serie de teoría jurídica y filosofía del derecho núm. 48, Bogotá, 2007, pp. 24 y 25. Similares consideraciones en F. Lanchester, Momenti e figure nel Diritto costituzionale in Italia e in Germania, Giuffrè, Milano, 1994, pp. XII y XIII; F. Lanchester, Pensare lo Stato. I giuspubblicisti nell'Italia unitaria, Laterza, Roma-Bari, 2004, p. VII; B. Sordi, “Recent studies of Public Law History in Italia (1992-2005)", en Zeitschrift für Neuere Rechtsgeschichte, 2007, pp. 274-276. Entre nosotros han manifestado una sensibilidad similar A. Nieto, Los primeros pasos del Estado constitucional, Ariel Derecho, Barcelona, 1996, pp. 12 y 13; J. L. Carro Fernández-Valmayor, "La doctrina clásica alemana sobre la personalidad jurídica del Estado. Notas para una relectura”, en AA. VV, Administración instrumental. Libro homenaje al Profesor Clavero Arévalo, Madrid, Civitas, 1994, p. 849; E. García de Enterría, Dos estudios sobre la usucapión en el Derecho administrativo, $4^{\text {a }}$ edición, Civitas, Madrid, 2007, pp. 19 y 20, señalando que "solo el campo totalizador de la historia puede ilustrarnos sobre la efectiva función política y social de las instituciones" y L. Martín Rebollo, El proceso de elaboración de la Ley de lo contencioso-administrativo de 13 de septiembre de 1888, Instituto de Estudios Administrativos, Madrid, 1975, p. 32, afirmando que "la referencia histórica no es una mera elucubración erudita sobre un pasado muerto, sino que tienen también (... ) una proyección de futuro en cuanto contribuye a la interpretación del presente".
} 
A ello coadyuvó, también, la peculiar configuración del sistema administrativo inglés, caracterizado por una debilidad o quasi-ausencia de una Administración central que erigió, a modo de contrapeso, una extensa Administración local que, en realidad, abarcaba la generalidad de funciones que en el continente eran propias del Estado $^{4}$. El Municipio inglés ha respondido tradicionalmente al prototípico selfgovernment, según el cual la unidad local de vida era el Municipio, que se fue desarrollando en el marco de la evolución total del Estado -con su ejemplar proceso de democratización de las instituciones políticas y sociales-, según sus mismos ideales políticos, y con las mismas preocupaciones propias del gobierno representativo (véanse la Municipal Corporation Act de 1835, reformando parte de los antiguos Boroughs en una senda de modernización y democratización, la Municipal Corporations Consolidation Act de 1882 o el Local Government Bill de 1888, que revisaba las formas de elección local y creaba nuevos organismos administrativos) ${ }^{5}$. La administración local inglesa conjugaba, de este modo, el principio representativo con la eficacia positiva del servicio público.

En este sentido, recuérdese también que el sistema inglés -como el americanorespondía al tipo de régimen local basado en el particularismo y la variedad, por oposición al tipo de unidad y uniformidad propio de los pueblos latinos, particularmente Francia y España ${ }^{6}$. En Inglaterra el concepto legal de Municipio no coincidía con el núcleo local real de vecindad, dado que no toda comunidad de esta naturaleza tenía la consideración legal de Municipio: como señalaba Posada, el Municipio inglés "no

4 J. Stevenson, "De la filantropía al fabianismo”, en AA.VV, Ensayos fabianos sobre el pensamiento socialista, Ministerio de Trabajo y Seguridad Social, Madrid, 1988, p. 41, afirmando que "durante gran parte del siglo XIX decir gobierno en Gran Bretaña equivalía a decir gobierno local”. Véase también R. Boverat, Le socialisme municipal en Anglaterre et ses résultats financiers, 10 ed., Arthur Rousseau, Paris, 1912, p. 46; M. Pérez Olea, “La crisis del Régimen local inglés”, REVL 1956, núm. 86, p. 172; M. Cuchillo Foix, La reforma del régimen local en Inglaterra y Gales, Instituto de Estudios de Administración Local, Madrid, 1987, pp. 19 y 20 y E. García de Enterría, “La actividad industrial y mercantil de los municipios”, RAP 17, mayo-agosto 1955, pp. 87-138, pp. 100-104. Como bien indicaba este último autor, ello era consecuencia de la resolución a favor de las ciudades de la pugna histórica entre la Monarquía centralizadora e instancias exentas de las ciudades y la nobleza, mientras la Europa continental se había inclinado a favor de la Monarquía.

5 Con detalle sobre el régimen municipal inglés y sobre las implicaciones que tuvieron las leyes de 1835 y las subsiguientes reformas A. Shaw, “The municipal government in Great Britain”, Political Science Quarterly, vol. 4, n² 2, June 1889, pp. 198-220 y R. Boverat, Le socialisme municipal en Anglaterre..., cit., pp. 48-50. Véase también A. Posada, “La democracia y el servicio público en el régimen municipal”, en A. Posada, Escritos municipalistas de la vida local, Instituto de Administración Pública, Madrid, 1979, pp. 197-210 (publicado por primera vez en la Revista General de Jurisprudencia y Legislación, tomo 127, julio-agosto 1915), p. 208; A. Posada, “La ciudad moderna”, en A. Posada, Escritos municipalistas de la vida local, Instituto de Administración Pública, Madrid, 1979, pp. 317-409, pp. 363-366; M. Cuchillo Foix, La reforma del régimen local en Inglaterra..., cit., pp. 25-31 y 60-80 y P. Dogliani, "Il dibattito sulla municipalizzazione in Europa dall'inizio del novecento alla prima guerra mondiale”, en A. Berselli / F. della Peruta / A. Varni (a cura di), La municipalizzazione in area padana. Storie ed esperienze a confronto, Franco Angeli, Milano, 1988, p. 223. Esta autora señalaba que para S. Webb la Municipal Corporation Act de 1835 había creado "several hundred energetic centres of local socialist developments", poniendo de relieve la relación entre organización local, democratización y desarrollo social.

6 A. Posada, “El Municipio", en A. Posada, Escritos municipalistas de la vida local, Instituto de Administración Pública, Madrid, 1979, pp. 239-258 (publicado por primera vez en la Enciclopedia Jurídica Española Seix, tomo XXIII), p. 253. 
es un molde inmutable que comprende una comunidad de determinada naturaleza y volumen particulares", sino una categoría histórica7.

De la conjunción de ambos factores surgió un régimen local inglés que, a lo largo del siglo XIX y hasta la Segunda Guerra Mundial, ostentó una situación hegemónica como gestor de los más variados y fundamentales servicios públicos. La magnitud del papel que entonces desempeñaban los entes locales en la vida de los ciudadanos ingleses suele expresarse, hoy en día, con un célebre fragmento atribuido a Sidney Webb, fundador de la Fabian Society y de la London School of Economics and Political Science:

“John Smith -decía Webb- se despierta en la vivienda que le ha proporcionado el Municipio por las campanas del reloj municipal. Enciende la luz eléctrica de la fábrica municipal, hace su aseo con el agua del abastecimiento municipal y bebe un vaso de leche certificada municipal, calentada con el gas de la fábrica municipalizada. En la calle, naturalmente municipal, toma el tranvía o el autobús municipal. Gracias a la policía municipal llega seguro a su oficina. Smith comerá posiblemente en un restaurante municipal, leerá los periódicos o revistas en una biblioteca pública, contemplará las obras de arte de un museo municipal, practicará el deporte en un parque municipal, consumirá alimentos conservados en las cámaras frigoríficas municipales, y distribuidos en los mercados municipales o tal vez en las expendedurías reguladoras del mismo carácter. Si no pertenece a la clase bastante pudiente de la ciudad, será asistido y hospitalizado en los establecimientos o por los facultativos municipales, y allí dará a luz su mujer. Cuando se encuentre sin trabajo, acudirá a la oficina municipal de colocación. Y habrá realizado sus estudios en las escuelas municipales. Un día, como todos los humanos, John Smith morirá, y, después de la inscripción en el Registro municipal, será llevado por el servicio fúnebre municipal al cementerio municipal"».

\section{LA EVOLUCIÓN DE LA MUNICIPALIZACIÓN EN INGLATERRA: DE LA COMPETENCIA (IN)EFECTIVA AL MONOPOLIO REGULADO Y DEL MONOPOLIO REGULADO A LA MUNICIPALIZACIÓN}

La historia del industrialismo municipal en Inglaterra tuvo su origen en el ámbito del abastecimiento de agua y gas, al que rápidamente habrían de sumarse los sectores de la electricidad y los transportes urbanos?.

$7 \quad$ A. Posada, "El Municipio", cit., p. 254. En efecto, el resultado final no era una serie de Municipios recogidos (y subordinados) en departamentos o provincias en tanto que división general administrativa del Estado, sino un conjunto de circunscripciones y entidades diversas como condados, distritos urbanos y rurales, parroquias, burgos municipales, uniones, etc.

8 La cita en L. Jordana de Pozas, “El problema de los fines de la actividad administrativa”, RAP 4, enero-abril 1951, pp. 11-28, p. 17, quien tuvo la suerte “de contarse entre los alumnos de régimen local de Webb”. Por su parte, Pérez Olea señalaba que la situación a la que se había llegado era "impresionante”, al estar en manos de los Municipios, total o parcialmente, "casi todas las carreteras, la inmensa mayoría de los aeródromos, los hospitales, parte de la seguridad social, la recaudación de impuestos y la determinación de sus bases, los transportes por carretera, la electricidad y el gas", lo que evidentemente implicaba una gran masa de funcionarios al servicio de este régimen y un gasto público local elevadísimo, que llegó a suponer la cuarta parte de los gastos públicos del Reino Unido. Cfr. M. Pérez Olea, “La crisis del Régimen local inglés”, cit., pp. 172 y 173, nota 6.

9 J. Warren, Municipal Trading, The labour publishing company limited, London, 1923, p. 13. 
Ciertamente, algunas ciudades gestionaban, con anterioridad al siglo XIX, mercados y mataderos, e incluso habían emprendido el suministro de agua a sus poblaciones. Sin embargo, no puede afirmarse que se tratara de una actividad propiamente empresarial. En este sentido, es a principios del siglo XIX cuando debemos situar las primeras actuaciones calificables como industrialismo municipal, coincidiendo con la aparición y el desarrollo de grandes núcleos y aglomeraciones urbanas, en las que se hacía necesaria la provisión de agua, luz o transporte, asumiendo estas actividades, ahora sí, un carácter eminentemente industrial ${ }^{10}$.

En esta primera época destacó la labor no tanto -como podría pensarse- de las figuras tradicionales del Alcalde o Mayor, de los Aldermen o de los Councillors, sino la de la denominada figura de inspector o Commissioner (el Lighting, Watching, o Paving Commissioner). Se trataba, normalmente, de personas importantes de los núcleos urbanos a los que se encargaba velar por la provisión de los servicios de abastecimiento de luz, alcantarillado, etc. Lo cierto es que algunos de estos órganos fueron realmente avanzados a su tiempo, al manifestar claramente su voluntad de responsabilizarse de la prestación de ciertos servicios, fundamentalmente el suministro de agua y gas ${ }^{11}$.

Así por ejemplo, el Commissioner de Leeds empezó a suministrar agua a partir de 1790. Especialmente relevante fue la actuación de los Commissioners de Manchester en relación con la producción y suministro de gas para uso municipal. En efecto, cuando en 1805 William Murdoch introdujo el alumbrado de gas en las fábricas de tejido de algodón de Salford, suprimiendo las velas y el aceite y reduciendo los gastos, los Commissioners del Municipio de Manchester recogieron la idea y, primero sin ningún tipo de apoyo o protección jurídica, y luego utilizando los poderes parlamentarios de que fueron investidos, montaron una fábrica de gas para el alumbrado de la ciudad y, desde 1817, para el consumo particular ${ }^{12}$.

Puede afirmarse sin ambages que los Commissioners de la ciudad de Manchester se avanzaron a su tiempo, sobre todo si tenemos presente que señalaron expresamente que asumían la fabricación del gas porque no era conveniente "confiar la prestación y el control del servicio de agua, del que dependían la salud y el bienestar de los habitantes del Municipio, a personas cuyo único objetivo era el propio interés, en función exclusivamente del cual iban a gestionar su empresa"13. Ahora bien, no debe-

10 J. Warren, Municipal Trading, cit., p. 13.

11 J. Warren, Municipal Trading, cit., p. 14.

12 Teniendo en cuenta que se trataba de una época de pleno auge del laissez-faire, era lógico que los Commissioners encontraran una vigorosa resistencia a su actuación; a pesar de ello, siguieron adelante y, si bien durante los primeros años tuvieron que gestionar su fábrica de gas sin ningún tipo de reconocimiento jurídico, lograron obtener los statutory powers a partir de 1824. J. Warren, Municipal Trading, cit., p. 14. Además, en años posteriores se irían sumando otras ciudades: Keighley en 1824; Beverley y York en 1825; Salford en 1839 o Stockport en 1838. Véanse las referencias en E. Ibáñez Papell, Servicios públicos municipales: organización y aspectos económicos, con un estudio de la municipalización del abastecimiento de leche, Barcelona, Bayer Hnos. y Comp., Barcelona, 1940, p. 13.

13 J. Warren, Municipal Trading, cit., p. 14; R. Boverat, Le socialisme municipal en Anglaterre..., cit., 
mos olvidar que su actuación fue, durante años, una excepción en un panorama dominado por la actuación de las empresas privadas. En este sentido, prácticamente todo el primer tercio del siglo XIX se caracterizó, en Inglaterra, por una creciente oposición entre los consumidores y las empresas privadas, que actuaban libremente en los diversos mercados. Fue precisamente este enfrentamiento lo que puso de relieve, de forma cada vez más evidente, las potenciales ventajas de la municipalización de dichos servicios ${ }^{14}$.

No puede olvidarse que los servicios en juego (suministro de gas, agua, transportes) presentaban dos características peculiares. Por un lado, todas ellos requerían inversiones iniciales importantes, en la medida en que para la provisión del servicio era preciso instalar, con carácter previo, canalizaciones, hilos o conducciones de distribución del servicio. Por otro lado, en la gran mayoría de los casos las empresas interesadas en hacerlo necesitaban una autorización por parte de los poderes públicos, puesto que dichas canalizaciones o conducciones atravesarían suelo público ${ }^{15}$.

Así, si bien hubo una primera fase en la que se otorgaban Private Acts a todas las empresas de gas o agua que lo solicitaran, pronto se observó que ello suponía un despilfarro inútil para los empresarios y que tampoco favorecía a los consumidores. En efecto, por lo que se refería a las empresas privadas, estas acababan construyendo en una misma calle o zona las mismas instalaciones, lo que suponía dos o más inversiones iniciales de capital, que solían ser muy costosas. Por su parte, los consumidores, aunque pagaban un precio relativamente bajo debido a la competencia, no era todo lo bajo que hubiera podido ser, puesto que cada empresa cargaba en su precio los costes de instalación, por lo que el consumidor acababa soportando en el precio que pagaba dos o más capitales de instalación y mantenimiento ${ }^{16}$.

Estos servicios, además, seguían la teoría de las economías decrecientes de escala, por lo que tendían fatalmente al monopolio, de manera que quien obtenía en primer lugar la autorización se colocaba en una posición de ventaja respecto de otras posibles competidoras que pretendieran entrar en el mercado posteriormente. Por lo tanto, con cierta rapidez se pasó de una situación de competencia efectiva a una situación tendente o cercana al monopolio ${ }^{17}$.

Por ello, a esta primera fase de libertad en la instalación de empresas suministradoras siguió una segunda etapa caracterizada por un movimiento tendente a la unión entre las empresas competidoras, o bien al reparto de zonas de influencia y suminis-

14 J. Warren, Municipal Trading, cit., p. 15.

15 J. Warren, Municipal Trading, cit., p. 16; A. Shaw, "The municipal government in Great Britain", cit., p. 220; R. Boverat, Le socialisme municipal en Anglaterre..., cit., pp. 64 y 65. Entre nosotros ha destacado estas dos peculiaridades F. Albi Cholbi, Tratado de los modos de gestión de las corporaciones locales, Aguilar, Madrid, 1960, pp. 71 y 72.

16 J. Warren, Municipal Trading, cit., pp. 16 y 17.

17 J. Warren, Municipal Trading, cit., p. 18. 
tro. Así por ejemplo, en 1860 las trece compañías suministradoras de agua en Londres presentaron al Parlamento un Bill solicitando, básicamente, el reparto del suministro por distritos ${ }^{18}$.

Sin embargo, esta etapa en la que predominaron los monopolios sin restricción o limitación por parte de los poderes públicos generó también graves inconvenientes, sobre todo para los consumidores, que tenían que soportar, casi siempre sin posibilidad de elección, los precios monopolísticos impuestos por los concesionarios y, también con demasiada frecuencia, una prestación deficiente en cantidad, calidad, o ambas. Warren ponía de relieve, en este sentido, que entre los años 1821 a 1840 se plantearon numerosas quejas a los Select Comittees o a las Royal Commissions por parte de consumidores -que actuaban a través de las autoridades locales-, estando la mayoría de ellas bien fundadas, por lo que tales órganos proponían, sistemáticamente aunque sin éxito, la necesidad de establecer una normativa reguladora ${ }^{19}$.

Finalmente, la Royal Commission of The Health of Towns informó muy negativamente sobre el abastecimiento de agua potable en las principales ciudades inglesas, poniendo especial énfasis en las consecuencias ruinosas que la competencia entre empresas había ocasionado, recomendando la limitación de la misma y el establecimiento de condiciones y límites a las empresas concesionarias ${ }^{20}$.

Gracias en parte a la actuación de esta Comisión, se aprobaron en 1845 y 1847 las Waterworks and Gasworks (clauses) Acts, que establecieron limitaciones a los dividendos que podían obtener las concesionarias (un máximo del 10\%), así como también unos mínimos estándares de calidad. Puede decirse, con Warren, que es a partir de estas fechas cuando se oficializó la fase del monopolio regulado en Inglaterra, al considerarse ya de forma oficial que la competencia tenía resultados despilfarradores y poco económicos ${ }^{21}$.

A partir de entonces, el camino hacía la municipalización de servicios quedaba trazado. En efecto, no tuvo que pasar mucho tiempo para que surgiera un movimiento general a favor de la prestación municipal de los principales servicios, comenzando por el abastecimiento de agua potable, de modo que numerosas ciudades empezaron a adquirir las instalaciones existentes mediante acuerdos con las empresas privadas.

Puede afirmarse, pues, que en Inglaterra, desde mediados del siglo XIX, se empezó a consagrar un sistema de actividad industrial y mercantil de los Municipios, en

18 J. Warren, Municipal Trading,. cit., p. 19; R. Boverat, Le socialisme municipal en Anglaterre..., cit., pp. 66 y 67, señalando que en Oxford Street llegaron a existir conducciones de hasta seis empresas privadas diferentes.

19 J. Warren, Municipal Trading, cit., p. 20; F. Albi, Tratado de los modos de gestión..., cit., pp. 71 y 72.

20 J. Warren, Municipal Trading, cit., pp. 20 y 21. 18 p. $68.21 \quad$ J. Warren, Municipal Trading, cit., p. 21; R. Boverat, Le socialisme municipal en Anglaterre..., cit., 
virtud del cual estos pasaron a gestionar los nuevos servicios técnicos que el desarroIlo industrial ofrecía como solución a la concentración urbana ${ }^{22}$.

El principal ejemplo y punto de partida había sido la ciudad de Birmingham, que bajo la dirección del empresario liberal Joseph Chamberlain -elegido Alcalde de la ciudad en 1873- había procedido en 1874 a municipalizar la distribución hídrica y, poco después, también los servicios de alumbrado a gas y eléctrico y los tranvías urbanos, además de demoler los barrios insalubres y construir nuevas barriadas para obreros a precios más asequibles. El éxito fue tal -se ha dicho que con Chamberlain dio verdadero inicio la denominada era del industrialismo municipal- que tomaron su ejemplo otras grandes ciudades inglesas, para luego extenderse a muchos otros países ${ }^{23}$.

Una de las ciudades que siguió el ejemplo de Birmingham fue Glasgow, realizando el primer saneamiento público de áreas edificables. En relación con esta ciudad, el periodista americano Albert Shaw, tras haber pasado unos meses en Europa, publicó en 1895 un volumen titulado Municipal Government in Great Britain. Junto a una primera parte dedicada a la nueva autoridad metropolitana de la capital inglesa (London County Council) y a la actividad social de centros importantes como Liverpool, Bradford, Sheffield, Nottingham, Leeds o Salford, se concentraba sobre tres casos particulares, siendo uno de ellos Glasgow (los otros eran Manchester y Birmingham).

Así, Shaw indicaba que Glasgow era una ciudad que había doblado su población en 25 años, alcanzando casi un millón de habitantes en 1891, y se había afianzado como un moderno polo comercial y productivo, lo que había derivado en una urgente necesidad de elaborar una política urbanística y de vivienda. Con esta finalidad se había creado un Health Department's Work para la lucha contra las epidemias y la desinfectación de viviendas, se había procedido a la construcción de viviendas populares y se había activado un sistema de inspección nocturno. Además, se había también implantado un sistema de iluminación pública muy extenso, y se había garantizado el suministro hídrico con tarifas reducidas respecto a las que había aplicado la empresa concesionaria que había gestionado el servicio hasta 1865; finalmente, se había también establecido un servicio propio de ómnibus, que concurría con las de-

22 E. García de Enterría, “La actividad industrial y mercantil...”, cit., pp. 100-104.

23 T. Elorrieta y Artaza, La municipalización de servicios en el Condado de Londres, Conferencia del 13 de marzo de 1919, Imprenta municipal, Madrid, 1919, p. 10; R. Boverat, Le socialisme municipal en Anglaterre..., cit., pp. 136-145; P. Dogliani, “Il dibattito sulla municipalizzazione in Europa...”, cit., p. 223. En este mismo sentido, Lucarini ha señalado que la importancia y la fama de Birmingham no radicó tanto en el nivel de desarrollo y satisfacción de problemas sociales o de la gestión de servicios públicos en red (que fueron superiores, por ejemplo, en ciudades como Glasgow o Manchester) sino en el hecho de haber sido la primera ciudad inglesa en iniciar el movimiento de expansión de las funciones locales, lo que condujo a que se la conociera como "La Meca” por todos aquellos que propugnaban el desarrollo del movimiento municipal. F. Lucarini, “La nascita delle scienze comunali tra Italia ed Europa. L'esempio della municipalizzazione dei servizi pubblici locali (1894-1914)”, en P. Dogliani / O. Gaspari (a cura di), L'Europa dei comuni dalla fine dell'Ottocento al secondo dopoguerra, Donzelli, Roma, 2003, p. 204. 
más líneas gestionadas en concesión ${ }^{24}$. Como ha señalado Pedregal y Fernández, la ciudad de Glasgow merece una mención especial precisamente por el rápido florecimiento que en ella adquirió la municipalización de servicios ${ }^{25}$.

Tras estos primeros ejemplos, el impulso municipalizador inglés se produjo definitivamente en la década de los ochenta y continuó durante todo el último decenio del siglo XIX, facilitado además, como se dijo, por una legislación particularmente favorable a la descentralización administrativa, a la autonomía económica de los Municipios y a su intervención en sectores considerados de interés público, como la instrucción, la higiene, la sanidad o la construcción ${ }^{26}$.

La organización comercial de los servicios municipalizados adquirió un nivel técnico elevado y de gran perfección, asemejándose al funcionamiento de las empresas privadas. El servicio lo llevaban funcionarios técnicos y bien retribuidos, elegidos entre los mejores que se hubieran presentado al correspondiente anuncio en las publicaciones técnicas y oficiales ${ }^{27}$. La dirección estaba en manos de Comités especializados en cada una de las materias, que a su vez constaban de subcomités técnicos y financieros. En cada servicio había por regla general un ingeniero jefe, completamente independiente de los otros servicios. Desde este punto de vista, la administración de los servicios municipalizados en Inglaterra se caracterizaba por la ausencia de toda preocupación socialista (o de otro cariz político), situándose totalmente al margen de la política ${ }^{28}$.

La municipalización en Inglaterra se distinguía principalmente por explotar los servicios comercial y autónomamente respecto de la administración ordinaria municipal. Así, el capital del servicio era independiente de la Hacienda local, y por tanto sus deudas tampoco afectaban al Municipio -era la propia empresa municipalizada quien pagaba sus servicios y demás gravámenes, como lo haría cualquier otra sociedad-,

24 F. Lucarini, “La nascita delle scienze comunali tra Italia ed Europa...”, cit., p. 203. También sobre ello A. Shaw, "The municipal government in Great Britain”, cit., pp. 226 y 227.

25 M. Pedregal y Fernández, Municipalización Comparada, Tipografía de Archivos, Madrid, 1930, p. 34 .

26 P. Dogliani, “Il dibattito sulla municipalizzazione in Europa...”, cit., p. 223.

27 M. Pedregal y Fernández, Municipalización Comparada, cit., p. 35. En relación con el personal empleado en las empresas municipalizadas hay que señalar que, con carácter general, solía provenir de clases sociales acomodadas, con una fortuna personal más allá de la media, y con gran experiencia en asuntos empresariales, contribuyendo directamente a potenciar la facturación y poniendo a disposición de la empresa pública sus propias capacidades empresariales a cambio de incentivos salariales y premios. Precisamente, los (por lo general) elevados salarios de los funcionarios públicos fueron el centro de las discusiones del Congreso socialista inglés de 1899, y en este el propio Webb -junto con algunos consejeros del London County Council- los justificó, en clara oposición a la mayoría de los consejeros provenientes de partidos y asociaciones socialistas o reformistas (Independent Labour Party y Social Democratic Federation). Webb sostenía que para poder contar en el sector público con técnicos y administradores válidos había que pagarles bien e incentivarles, como se hacía en la industria privada, concediéndoles comisiones y primas -como permitía, por demás, la legislación inglesa- aunque siempre sujetas al control del balance de la empresa. P. Dogliani, “Il dibattito sulla municipalizzazione in Europa...”, cit., p. 234.

28 M. Pedregal y Fernández, Municipalización Comparada, cit., p. 35. 
aunque no por ello dejaban estas de ser inspeccionadas detalladamente, recayendo en todo caso la responsabilidad sobre los administradores. Por otra parte, tanto las cuentas como todas las operaciones del servicio eran públicas y estaban a disposición de los contribuyentes de la ciudad, como si fueran pequeños accionistas de una gran sociedad privada ${ }^{29}$.

Ahora bien, no se trataba de una autonomía absoluta, puesto que cada servicio quedaba sometido, además de a la inspección de una Comisión o Comité director, a la inspección anual por parte de dos delegados del Consejo municipal y al eventual examen de las autoridades centrales -para la comprobación de que no se había extralimitado en sus atribuciones-, que ejercían así una tutela administrativa en el sentido de crítica o censura ${ }^{30}$.

En cualquier caso, conviene señalar que las municipalizaciones inglesas no presentaron, en ningún momento, la complejidad propia de otros ordenamientos en cuanto a las formas de gestión o prestación del servicio. El sistema inglés contemplaba básicamente la posibilidad de que fuera el Municipio quien, a través de un órgano específico dotado de autonomía financiera y de gestión, se encargara de la prestación de un determinado servicio.

\section{ESTUDIO PARTICULARIZADO DE LOS DIVERSOS SERVICIOS MUNICIPALIZADOS}

\subsection{Tranvías ${ }^{31}$}

Mediante la Liverpool Tramways Act de 1868 el Parlamento inglés concedió a una compañía privada la explotación de los tranvías para el Municipio de Liverpool, aunque otorgando también al Municipio la facultad de proceder, dentro de ciertas condiciones, al rescate de esta u otras concesiones de tranvías que se pudieran otorgar a compañías privadas. Al año siguiente se dispuso lo mismo para la ciudad de Londres. Sin embargo, el procedimiento de los Private Bill era largo y costoso, por lo que en 1870 el Parlamento aprobó una ley general, la Tramways Act que, además de simplificar los costes y la duración del proceso, tuvo una notable influencia sobre el desarrollo de los servicios públicos en el Reino Unido. Dicha norma contem-

29 M. Pedregal y Fernández, Municipalización Comparada, cit., pp. 36-38; L. Waldman, The Great collapse: higher fares or public ownership, New York, 1919, pp. 200 y 201, enfatizando la similitud respecto de la empresa privada, en concreto para el caso de los tranvías urbanos.

30 M. Pedregal y Fernández, Municipalización Comparada, cit., pp. 37-39.

31 Seguimos sustancialmente en nuestra exposición los trabajos de R. Boverat, Le socialisme municipal en Anglaterre..., cit., pp. 177-191; A. Geisser, Fatti ed argomenti intorno alla municipalizzazione, Estratto dalla Riforma Sociale, Fasc. 1 Anno XVI, Vol. XX -Gennaio-Febbraio 1909, Società tipogradico-editrice nazionale, Torino, 1909, pp. 54-57; J. Gascón y Marín, Municipalización de servicios públicos, Librería General Victoriano Suárez, Madrid, 1904, pp. 177-190. Recientemente le ha dedicado algunas páginas a esta perspectiva histórica A. Ruiz Ojeda, La concesión de obra pública, Thomson-Civitas, Cizur Menor, Navarra, 2006, pp. 134-146. 
plaba dos modalidades de concesión -entendida en sentido laxo ${ }^{32}$ - para los empresarios privados:

a) Las Provisional Orders, concedidas por el Board of Trade (equivalente al Ministerio de Obras públicas). Estas concesiones provisionales o preliminares necesitaban, para convertirse en definitivas, de la aprobación del Parlamento, estableciéndose como requisito para su presentación que los solicitantes comprobaran, con carácter previo, la existencia de consenso entre las autoridades locales en, al menos, dos tercios del desarrollo total de la línea.

b) En segundo lugar, los solicitantes podían acudir al Parlamento directamente con un Private Bill, esto es, un proyecto de ley de interés particular o local, para el cual se preveía un procedimiento largo y costoso. Las dos Cámaras parlamentarias habían establecido, de mutuo acuerdo, una Standing Order, esto es, una norma reglamentaria en su procedimiento interno, en virtud de la cual los Private Bills no serían admitidos a debate sin que se hubiera comprobado antes el asentimiento de las autoridades locales en la misma proporción exigida para las Provisional Orders del Board of Trade.

De este modo, prácticamente se reconocía por el Parlamento un derecho de veto a las autoridades locales, cualquiera que fuese la vía utilizada para obtener una concesión tranviaria.

La Tramways Act había establecido, también, una duración máxima de 21 años para las concesiones, plazo computable no desde el inicio del ejercicio sino desde la fecha de la concesión definitiva, así como también había conferido a las autoridades locales la facultad para rescatar el servicio al acabar la concesión. El rescate se calculaba sobre la base del valor físico de la instalación, o sea, se pagaba el valor que el tranvía habría tenido al acabar la concesión, excluyendo cualquier pago por los beneficios pasados o futuros de la empresa, así como también cualquier pago de tipo indemnizatorio por la cesión forzosa o por cualquier otro título. Transcurrido el plazo de la concesión, las autoridades locales podían aún rescatar, siempre sobre la base de este modo de valoración, cada siete años subsiguientes ${ }^{33}$.

32 Se ha optado por traducir las diversas figuras inglesas mencionadas en texto por el genérico término de “concesión”, aún cuando se es consciente de que desde una perspectiva estrictamente jurídica no se trata de términos equivalentes. Sin embargo, esta fue la opción que acogieron los autores continentales que entonces estudiaron la materia (Boverat, Geisser o el mismo Gascón y Marín). Asimismo, es la opción que acogen estudios más recientes, entre ellos E. García de Enterría, “El servicio público del gas” en E. García de Enterría, Problemas actuales del régimen local, $3^{\circ}$ edición, Thomson-Civitas, Madrid, 2007, p. 74, y A. Ruiz Ojeda, La concesión de obra pública, cit., p. 136.

33 Se ha señalado que esta regulación traía causa del deseo, por parte del Parlamento, los Municipios y la opinión pública, de impedir que se repitieran los inconvenientes ocasionados por las concesiones de gas, que no se habían acompañado de plazos ni de modalidades de rescate y que habían derivado, por 
La ley también permitía a las autoridades municipales solicitar la concesión y construir las instalaciones, pero prohibía la explotación directa de los tranvías, salvo que se probara la imposibilidad de encontrar a algún particular que, de modo permanente, quisiera explotar el servicio. No obstante, con el paso del tiempo algunos Municipios fueron obteniendo autorizaciones especiales para explotar directamente sus líneas (el primer Municipio fue Huddersfield, en virtud de la Huddersfield Improvement Act de 1882) $)^{34}$, y desde 1896, mediante una derogación tácita de esta prohibición por parte del Parlamento, la municipalización fue admitida sin reservas, existiendo al comenzar el siglo casi tantas líneas municipales como particulares (Glasgow en 1894, Liverpool en 1897, Manchester en 1901, Birmingham en 1904).

Por otra parte, ese mismo año el Parlamento aprobó la Light Railways Act, cuyo objetivo era poner remedio a la grave crisis agrícola que afectaba al país mediante una mejoría en los medios de transporte. Debía permanecer en vigor cinco años a título experimental, aunque luego fue constantemente renovada. No obstante, la ley no fue clara en su regulación ni aclaró tampoco qué debía entenderse por Light Railways (ferrovías económicas), por lo que sus disposiciones, más elásticas que las de la Tramways Act, se pudieron aplicar a la construcción de tranvías urbanos.

La ley delegaba en el presidente del Board of Trade la facultad para nombrar una Comisión de tres miembros a la que correspondería otorgar las concesiones. Estas concesiones, si el Board las confirmaba, tenían los mismos efectos que las autorizadas por ley del Parlamento, gozando de un procedimiento más rápido y menos costoso. La Comisión o el Board of Trade establecían, en el acto de concesión, la tarifa máxima para los transportes y las cláusulas que habilitaban a las autoridades locales a rescatar las ferrovías al caducar la concesión. Además, y a diferencia de la ley de 1870, la ley de 1896 no reconocía el derecho de veto a las autoridades locales por cuyo territorio debía pasar la ferrovía. Sin embargo, la Comisión acabó adoptando una posición que sustancialmente dejaba a salvo tal derecho.

Con estas regulaciones se pretendía claramente impulsar la municipalización de los tranvías, entendiendo que la construcción de nuevos barrios obreros y la extensión de las ciudades - para reducir el hacinamiento de sus habitantes- estaban íntimamente ligados a la construcción de líneas de transporte que conectaran el centro con los suburbios, así como con las tarifas económicas de las mismas ${ }^{35}$. A pesar de que ciertamente hubo detractores de la municipalización de los tranvías -básicamente,

34 Según señalaba Gascón y Marín, originariamente el servicio no fue demasiado exitoso, debido a los gastos que llevó consigo el sistema de tracción a vapor, y el déficit de los primeros años incluso hizo pensar en desistir. Sin embargo, parece que a partir de 1896 mejoró y se obtuvieron ganancias. Cfr. J. Gascón y Marín, Municipalización de servicios públicos, cit., pp. 177-190. Boverat, por el contrario, indicaba que el servicio tuvo siempre pérdidas considerables. R. Boverat, Le socialisme municipal en Anglaterre..., cit., pp. 186 y $191-193$.

35 T. Elorrieta y Artaza, La municipalización de servicios en el Condado de Londres, cit, p. 20. 
por las trabas que las leyes suponían para la empresa privada ${ }^{36}$ - la municipalización de los tranvías urbanos se extendió por casi toda Inglaterra.

\subsection{Casas baratas para obreros ${ }^{37}$}

Fue a mediados del siglo XIX cuando el Parlamento inglés comenzó a conceder autorizaciones a las autoridades locales para construir casas para obreros. Se empezaba a observar, por entonces, la relación existente entre higiene y salubridad, por un lado, y las condiciones de las viviendas en que se alojaban los habitantes de una ciudad. La mejora de las condiciones materiales de vida de los trabajadores fue incluida desde muy pronto en los programas de todos los partidos y asociaciones obreras.

Ante esta situación, se dictó en Inglaterra la Housing of the Working Classes Act (1890), que disponía la concesión a los Municipios de facultades para expropiar toda área urbana insalubre, destruir sus edificios y levantar otros higiénicos. La destrucción de cualquier edificio llevaba implícita la obligación de construir por el Municipio o el particular a quien este cediera sus derechos, tantas viviendas como familias hubieran habitado el barrio destruido.

Por otra parte, la ley concedía también a los Municipios facultades para desalojar las casas que no reunieran las debidas condiciones higiénicas, estableciendo expresamente que si no las arreglaba el propietario, podría derribarlas el Municipio si lo estimase conveniente, o expropiarlas y construir directamente casas para obreros. A tal efecto, la ley facilitaba recursos a los Municipios para que pudiera adquirir terrenos y edificar viviendas económicas.

En relación con esta política de construcción de viviendas económicas, se señaló que no siempre había logrado alcanzar y favorecer a las capas más bajas de la población, que continuaban, con frecuencia, viviendo hacinadas o bajo los puentes del río. Por otra parte, se puso también de relieve la notable retracción sufrida por la empresa privada, pues difícilmente los constructores consideraban que el negocio pudiera reportarles un beneficio suficiente, y ello a a pesar de las condiciones ventajosas que solían ponerse a su disposición para la construcción de estas viviendas ${ }^{38}$.

36 Estas críticas se hallan ampliamente recogidas en la obra de Avebury, Municipalización y nacionalización de los servicios públicos, traducción de la tercera edición inglesa a cargo de J. Pérez Hervás, Imprenta Eugeni Subirana, Barcelona, 1912, pp. 103-116 y también en la obra de su traductor al italiano A. Geisser, Fatti ed argomenti intorno alla municipalizzazione, cit., pp. 56-59. Críticas similares las recoge también R. Boverat, Le socialisme municipal en Anglaterre..., cit., pp. 181-184 y 217-220.

37 Seguimos sustancialmente en nuestra exposición, salvo indicación en contrario, los trabajos de R. Boverat, Le socialisme municipal en Anglaterre..., cit., pp. 241-253; T. Elorrieta y Artaza, La municipalización de servicios en el Condado de Londres, cit., pp. 17-19; J. Gascón y Marín, Municipalización de servicios públicos, cit., pp. 202-223.

38 Muy crítico con esta política fue Avebury, Municipalización y nacionalización de los servicios públicos, cit., pp 54-57, citando diversas cartas también críticas aparecidas en la época en The Times. 


\subsection{Agua}

A partir de 1845 empezaron a aprobarse una serie de normas (Water Act en 1845 y 1848; Gas and Water Works Act en 1870) que dieron inicio a la municipalización del abastecimiento de agua en Inglaterra. Es a partir de entonces cuando muchas de las grandes ciudades y núcleos urbanos comenzaron a rescatar sus concesiones (Sheffield en 1830, Manchester en 1847, Glasgow en 1855, Birmingham en 187639) o bien, si estas no existían, a construir directamente sus propias instalaciones (Bath, Coventry, Halifax, Plymouth).

De especial relieve fue la extensísima Public Health Act, aprobada en 1875 y que, consolidando algunas normas previas de 1848 y 1872, configuraba el inicio de un sistema sanitario local. Esta norma otorgaba poderes a los Consejos municipales para que ejercieran de autoridades sanitarias, nombrando un funcionario médico local (medical Officer of health) y un inspector para la higiene y la tranquilidad pública (Inspector of nuisances), y asumiendo la responsabilidad en el control de la red de alcantarillado, de la higiene de los edificios y de la asistencia médica de la población necesitada, así como también sobre cementerios, jardines públicos, mercados y mataderos, casas para obreros, etc. Les otorgaba asimismo, y con carácter general, la facultad para construir y explotar instalaciones de agua y gas (aunque no si ya existía en la zona una empresa ni previendo, tampoco, un derecho de rescate forzoso una vez transcurrido el plazo de duración de la concesión) $)^{40}$.

Así, en 1902 eran un total de 193 los Municipios ingleses y galeses que poseían sus propias fábricas de agua (entre ellas Bath, Coventry, Halifax, Hastings, Huddersfield, Hull, Liverpool, Oxford, Plymouth, Southampton, o Worcester), y por esas mismas fechas se contaban un total de 1905 empresas municipales de agua en todo el Reino Unido. Londres, uno de los Municipios que más tarde municipalizó el servicio, lo hizo también en 1902, con la creación del Metropolitan Water Board para el abastecimiento municipal de agua ${ }^{41}$.

La municipalización del servicio de agua se hacía, por regla general, sin ningún sistema fijo. Cuando un Municipio decidía que le convenía, en interés público, controlar la distribución de agua potable, entraba en negociaciones con las empresas

39 Sobre la ciudad de Sheffield en particular puede consultarse T. Willis, "Contributing to a real socialist commonwealth: municipal socialism and health care in Sheffield (1918-1930)", en U. Kühl, Der Munizipalsozialismus in Europa/ Le socialisme municipal en Europe, Parischen Historische Studien, Oldenbourg Verlag München, 2001, especialmente p. 103.

El proceso de municipalización del abastecimiento de agua potable en la ciudad de Glasgow se encuentra detallado en A. Shaw, “The municipal government in Great Britain”, cit., pp. 221 y 222 y en R. Boverat, Le socialisme municipal en Anglaterre...,. cit., pp. 85-89. Este último autor también exponía el proceso en las ciudades de Manchester (pp. 94-98) y Birmingham (pp. 98-109).

40 P. Dogliani, “Il dibattito sulla municipalizzazione in Europa...”, cit., p. 223; J. Warren, Municipal Trading, cit., p. 21; R. Boverat, Le socialisme municipal en Anglaterre..., cit., pp. 51 y 52.

41 R. Boverat, Le socialisme municipal en Anglaterre..., cit., pp. 81-83. Véanse también las referencias de J. Gascón y Marín, Municipalización de servicios públicos, cit., pp. 139-151. 
concesionarias, llegando a un acuerdo amistoso o sometiendo la cuestión a un arbitraje. Aunque las leyes no otorgaban facilidades especiales para la transferencia de las empresas de agua desde el sector privado al público (no se preveía legalmente el rescate forzoso), la política habitual del Parlamento acabó siendo la de no denegar a ninguna autoridad local que pretendiera obtener el control de este servicio la correspondiente autorización, sobre la base de que se trataba de un servicio que entraba dentro de los deberes y responsabilidades del Municipio, que debía claramente velar para que sus ciudadanos estuvieran bien provistos de agua, en cantidad y en calidad suficiente ${ }^{42}$.

A partir de 1879 el Parlamento centró sus esfuerzos en garantizar la provisión de agua a los distritos extra-urbanos y radiales que rodeaban los grandes núcleos urbanos. En efecto, fue en esa fecha cuando Manchester obtuvo, mediante una Private $A c t$, la autorización para transformar el lago Thirlmere en una reserva de agua. En dicha norma el Parlamento estableció que los Municipios que se hallaran dentro de un cierto radio respecto de las conducciones hídricas de Manchester tenían derecho a exigirle la provisión del agua que necesitaran. De este modo, Manchester llegó a proporcionar agua potable a un territorio de 85 millas cuadradas, que suponía una población superior al millón de habitantes, cuando el solo Municipio apenas superaba el medio millón ${ }^{43}$.

\subsection{Gas}

Para la municipalización del gas no podían invocarse, a primera vista, las mismas razones que para el caso del agua, puesto que ni la higiene ni la salubridad y salud pública jugaban ciertamente el papel esencial que tenían para el abastecimiento de agua potable. Tal vez ello explique que la municipalización del gas, y el movimiento a favor de la misma, surgiera con posterioridad, consolidándose solo a partir de las décadas de los setenta y ochenta del siglo XIX. La principal razón que se esgrimió, originariamente, para la municipalización del gas fue la seguridad pública: la iluminación pública de las calles evitaría en buena medida los delitos y los desordenes públicos, cuyo número aumentaba en las grandes ciudades. Además, la posibilidad de producirlo a bajo precio y en grandes cantidades permitiría mejorar las condiciones de vida de los trabajadores, por ejemplo proporcionándoles calefacción en invierno ${ }^{44}$.

Los primeros Municipios que montaron fábricas para la producción y distribución de gas actuaron mediante autorizaciones o disposiciones parlamentarias específicas (Private Bills); fue algo más tarde cuando, finalmente, el Parlamento optó por aprobar disposiciones de tipo general, como la Gas Works Clause Act de 1847 y la Metropolitan Gas Act de 1860. Según algunas fuentes, las empresas gasistas obtenían

42 R. Boverat, Le socialisme municipal en Anglaterre..., cit., p. 82.

43 R. Boverat, Le socialisme municipal en Anglaterre..., cit., pp. 84 y 85.

44 R. Boverat, Le socialisme municipal en Anglaterre..., cit., pp. 117-119. 
notables beneficios -en este sentido, no era complicado, por la propia estructura y características del gas, producir con notables rendimientos financieros-, lo que contribuyó a favorecer la tendencia municipalizadora, y permitió, al mismo tiempo, una constante disminución de los precios.

Esta nueva legislación favorable a la municipalización llevaría a que, según las fuentes, entre 1844 y 1867 trece Municipios rescataran concesiones, número que fue de 68 entre 1869 y 1878. Así, indicaba Shaw que en 1887 un total de 166 Municipios ingleses poseían fábricas de gas ${ }^{45}$.

\subsection{Electricidad ${ }^{46}$}

Algunos años más tarde hizo su irrupción en el mercado del abastecimiento de luz la energía eléctrica. En 1882 Joseph Chamberlain, célebre municipalizador de la ciudad de Birmingham y entonces Ministro de Industria (Board of Trade) en el Gabinete Gladstone, presentó al Parlamento un proyecto de ley que contemplaba la posibilidad para los entes locales de otorgar concesiones a las compañías privadas, así como también la posibilidad de que el Board of Trade otorgara provisional orders por siete años sin necesidad de ratificación por parte del Parlamento (o por quince años con dicha ratificación). De este modo, a los concesionarios se les evitaban en el primer caso los gastos que suponía tener que defenderse frente a las numerosas alegaciones que, según Chamberlain, harían los entes locales ante el Parlamento. Asimismo, se preveía también que los entes locales pudieran rescatar las instalaciones a los 21 años, sobre la base del valor de sustitución (replacement value), esto es, al precio de coste de una instalación en iguales condiciones que una que se ejerciese al acabar la concesión.

La Cámara de los Lords instituyó una Comisión especial sobre el proyecto de ley y acabó enmendando el proyecto originario a través de la Electric Lighting Act de 1882, que constituyó el punto de partida para la municipalización de la electricidad.

La nueva ley determinaba que toda empresa que pretendiera colocar conducciones en suelo público debía obtener una autorización del Board of Trade, previo consentimiento de la autoridad local interesada. El Board podía emanar provisional orders sin el mencionado consentimiento o sin limitación temporal, pero estas debían luego, en todo caso, confirmarse con la ley del Parlamento, ante la cual cabía presen-

45 A. Shaw, "The municipal government in Great Britain”, cit., pp. 221, 223 y 224. Más datos y tablas estadísticas en R. Boverat, Le socialisme municipal en Anglaterre..., cit., pp. 120 y 121.

46 Seguimos sustancialmente en nuestra exposición, salvo indicación en contrario, los trabajos de R. Boverat, Le socialisme municipal en Anglaterre..., cit., pp. 154-176 y 221-225 (para la parte relativa a las empresas productoras y distribuidoras de fuerza motriz); A. Geisser, Fatti ed argomenti intorno alla municipalizzazione, cit., pp. 78-87; J. Gascón y Marín, Municipalización de servicios públicos, cit., pp. 151-177; J. Warren, Municipal Trading, cit., pp. 22-27. 
tar alegaciones. Además, la ley otorgaba al Board la facultad de prolongar la duración de las concesiones hasta un máximo de 21 años, autorizándose el rescate forzoso al término de la misma, y transcurrido dicho plazo, a intervalos sucesivos cada siete años. El precio del rescate venía fijado según las normas prescritas por la Tramways Act de 1870.

La ley daba al Board amplísimos poderes de regulación: fijaba la zona de competencia de cada concesionario, los precios máximos, las normas para el control de calidad y potencia de la luz, tenía facultad para revocar la concesión e, incluso, el mismo acto del Parlamento en caso de inobservacia por parte del concesionario de las cláusulas que se le habían impuesto. Asimismo, permitía otorgar autorizaciones para la instalación de iluminación eléctrica a las autoridades locales, con el privilegio de que en tales casos ninguna empresa privada podría obtener una concesión en el mismo distrito, de manera que aquellas gozaban, realmente, de un auténtico monopolio.

En 1886 el Ministro Salisbury, considerando la normativa de 1882 excesivamente rígida, propuso una enmienda en virtud de la cual se suprimía el rescate forzoso, se establecía una escala móvil de precios y beneficios (sliding scale) y se incrementaba la duración de las concesiones hasta un máximo de 42 años, con el objetivo de estimular la iniciativa privada. Parece ser que se registraron no pocos casos en los que un Municipio, habiendo rescatado una instalación gasista o habiéndola construido él mismo, temiendo los efectos que sobre la producción y distribución de gas pudiera tener el auge de la electricidad, optaba bien por ejercer su derecho de veto e impedir las concesiones a particulares, bien por solicitar él mismo la concesión para instalar una fábrica de energía eléctrica para luego no ejercerla. Ello conllevó fuertes críticas, al entenderse que se estaban poniendo trabas al progreso y a la innovación tecnológica, además de dañar fuerte y desmesuradamente a la empresa privada ${ }^{47}$.

La Cámara de los Lords estableció una Comisión para estudiar las propuestas, y, finalmente, en 1888 se modificó la ley ampliándose el plazo a 42 años y disponiéndose que si a los dos años de haberse otorgado la concesión esta aún no se había puesto en práctica, se entendería caducada. Esta reforma mantuvo, no obstante, el derecho de rescate al término de la concesión -pudiendo activarlo cada siete años- sobre la base del valor físico de la instalación, siguiendo aquí la misma cláusula prevista para los tranvías y las ferrovías económicas.

La modificación sí había suprimido el derecho de veto existente en la redacción originaria de 1882, de modo que ahora las autoridades locales únicamente podían presentar protesta contra las concesiones a empresas privadas otorgadas por el Board of Trade. No obstante, en la práctica, el Board of Trade solo muy raramente dejaba de tener en consideración la oposición de los entes locales.

47 Avebury, Municipalización y nacionalización de los servicios públicos, cit., pp. 120-135. A tales críticas se refiere también R. Boverat, Le socialisme municipal en Anglaterre..., cit., p. 158. 
Así las cosas, las primeras fábricas municipales de electricidad se instalaron en Bradford, Brighton y St. Panctras entre 1889 y 1891, generalizándose a partir de entonces y a lo largo de la década de los noventa y de la primera década del siglo $\mathrm{XX}^{48}$.

Además, desde principios de siglo empezaron a adquirir importancia las instalaciones generadoras de energía eléctrica para la provisión de luz y fuerza motriz, destinadas a proveer a más de un Municipio. Al empezar el siglo XX empezaron a formarse grandes compañías explotadoras de energía eléctrica que competirían con las pequeñas empresas privadas o municipalizadas que tenían que convertirse, en caso de subsistir, en monopolio. Entre 1900 y 1904 el Board otorgó a 24 compañías intermunicipales las concesiones para el suministro al por mayor de energía eléctrica a Municipios y a empresas distribuidoras locales. Las cláusulas previstas en las diversas concesiones tenían un alcance mayor o menor ${ }^{49}$, en función de la reacción que al respecto hubieran mostrado las autoridades locales implicadas, pero en todo caso, todas las concesiones intermunicipales a empresas privadas estaban sujetas a la cláusula que facultaba a las autoridades locales a rescatar pagando el valor físico y dentro de 42 años las líneas y las instalaciones existentes en el respectivo territorio.

\subsection{Otros}

En virtud de la Provision of Meals Act de 1906, todos los Municipios debían suministrar alimentos a los niños en las escuelas, para lo cual se les habían otorgado facultades que les permitieran exigir a los padres con un salario superior a una cierta cantidad, el pago de una contribución. Asimismo, se autorizaba a los Municipios a cobrar

48 Los datos de que disponemos difieren en este punto. Según Gascón y Marín, de las 709 orders concedidas hasta 1902, 476 lo habían sido a autoridades locales y 233 a particulares; 251 fábricas municipales funcionaban, 104 estaban en construcción y 121 sin utilizar. Cfr. J. Gascón y Marín, Municipalización de servicios públicos, cit., pp. 172-177. En cambio, según Geisser, a finales de 1904, había 294 concesiones a entes locales; en 105 de las cuales habían transcurrido entre 5 y 16 años entre la fecha de la concesión y la fecha de inicio del suministro de energía al público. Por el contrario, de 133 empresas privadas que habrían obtenido concesiones, 123 habían entrado en servicio en un plazo de 3 años. Cfr. A. Geisser, Fatti ed argomenti intorno alla municipalizzazione, cit., pp. 81-84. Por su parte, Boverat hablaba de 165 fábricas de electricidad municipales en explotación en 1901, cifra que ascendía a 244 en 1905, junto con 90 en construcción, mientras que para la misma fecha había 136 instalaciones privadas y 39 en construcción. R. Boverat, Le socialisme municipal en Anglaterre..., cit., pp. 154 y 158.

49 Así por ejemplo, la concesión a la empresa de Lancashire autorizaba a suministrar al por mayor a los Municipios y a las empresas distribuidoras, pero no podía prestar el servicio directamente a los particulares de un Municipio salvo que obtuviera autorización expresa para ello (una concesión de distribución local). Por otra parte, la concesión a la compañía de South-Wales autorizaba, en términos similares a la anterior, a prestar energía al por mayor también a Municipios y a empresas suministradoras. Asimismo, permitía también prestar energía a cualquiera para el uso de fuerza motriz o para el uso de iluminación de locales donde se emplease fuerza motriz, pero en ambos casos debía obtenerse previamente el consentimiento del Municipio y de la compañía que tuviera la concesión de distribución local. En caso que tal consentimiento le fuese negado, el Board podía, a pesar de ello, consentir la actuación de la sociedad si consideraba que el concesionario local no estaba en disposición de proporcionar la energía suficiente a los consumidores locales a precios y en cantidad o calidad suficiente. 
un impuesto extraordinario a todos los vecinos y a nombrar, para la gestión de este servicio, Comités de distrito ${ }^{50}$.

En Inglaterra, la industria telefónica estaba originariamente en manos de múltiples empresas privadas, de diverso tamaño, siendo la más importante la denominada National Telephone Company. En 1892 se aprobó una ley en virtud de la cual se otorgaba al Gobierno la facultad para rescatar las principales líneas telefónicas pertenecientes a empresas privadas, así como para establecer también un sistema general que uniera las ciudades más importantes del país. Paralelamente, la National Telephone Company adquirió las empresas existentes menos importantes, de modo que al final, aglutinó prácticamente a todas las empresas privadas con redes locales ${ }^{51}$.

La constitución de este trust monopolizador fue el pistoletazo de salida para una activa campaña en favor de los teléfonos municipales, solicitándose al Parlamento autorización para que los Municipios pudieran acometer el ejercicio directo del servicio. Tras el informe favorable de la Comisión parlamentaria designada al efecto en 1898, se aprobó la Telegraphs' Act en 1899, siendo Glasgow en 1901 la primera ciudad de cierta importancia que decidió municipalizar el servicio telefónico, si bien el pequeño Municipio de Guernesey ya había establecido su propia red municipal en $1898^{52}$.

Por lo que se refiere a asilos nocturnos (municipal lodging-houses), también Glasgow fue pionera en la prestación municipal del servicio, al establecer en 1870 varios de ellos a lo largo de la ciudad, en los que los acogidos podían permanecer 24 horas, facilitándoseles a un precio módico cama, baño y lavabo, así como uso de cocina, comedor y cuarto de lectura. En ocasiones, se trataba más de bien de casas familiares en las que vivían obreros viudos y viudas con sus hijos, que quedaban al cuidado del establecimiento mientras acudían al trabajo. El ejemplo de Glasgow fue seguido por varias ciudades, y en algunas de ellas los asilos llegaron a tener un ligero superávit, aunque la mayoría eran deficitarios y el Municipio tenía que cubrir las pérdidas ${ }^{53}$.

Hay que señalar que Glasgow y el resto de Municipios decidieron establecer este servicio no únicamente por cuestiones piadosas y asistenciales -de beneficencia o filantropía en el sentido clásico- sino también como un instrumento de policía y orden

50 T. Elorrieta y Artaza, La municipalización de servicios en el Condado de Londres, cit., p. 23. Dado que el coste de las comidas infantiles solía ser inferior a lo recaudado por ley, se ampliaba frecuentemente el servicio a la prestación de calzado a los escolares.

51 R. Boverat, Le socialisme municipal en Anglaterre...,. cit., p. 227.

52 R. Boverat, Le socialisme municipal en Anglaterre..., cit., pp. 231-240; J. Gascón y Marín, Municipalización de servicios públicos, cit., pp. 191-194. Señalaba este autor que, debido al coste claramente inferior del servicio municipal respecto del de la empresa particular, ya en 1900 el Municipio tenía el doble de número de abonados que la empresa particular.

53 J. Gascón y Marín, Municipalización de servicios públicos, cit., pp. 202-223; R. Boverat, Le socialis me municipal en Anglaterre..., cit., pp. 303-308, ofreciendo numerosos datos sobre las características de estos asilos en Glasgow, los servicios que se podían encontrar y las tarifas aplicables. 
público y también sanitario, al garantizar que los homeless y los trabajadores tuvieran unas mínimas condiciones de limpieza e higiene corporal.

La Bath and Watch Houses Act de 1846 permitió la municipalización de los baños públicos, que rápidamente se generalizaron -según el Municipal Year Book de 1906 era 225 Municipios los que en Inglaterra explotaban baños públicos, entre ellos Glasgow, Birmingham, Manchester o Liverpool-, normalmente a precios reducidos o incluso gratuitos. En este sentido, destacaba el acuerdo adoptado por el Municipio de Liverpool, en virtud del cual los inspectores de sanidad podían entregar entradas gratuitas a personas necesitadas para que pudieran utilizar estos establecimientos; asimismo, había establecido la posibilidad de que los menores de quince años pudieran bañarse gratis en pilas de natación, después de una limpieza con jabón y agua caliente ${ }^{54}$. Como norma general, los baños públicos ingleses ocasionaban un cierto déficit, fácilmente explicable por la finalidad que presidía la prestación de tales servicios.

Finalmente, otro caso muy conocido de municipalización en Inglaterra es el del Municipio de Saint Helens, que en 1899 decidió tomar a su cargo la venta de leche esterilizada, al haber observado que donde esta se utilizaba de forma generalizada la (elevada) mortalidad infantil había disminuido, y se había favorecido la alimentación de los recién nacidos ${ }^{55}$. El ejemplo de Saint Helens fue seguido por otros Municipios, entre ellos Liverpool, York, Belfast o Glasgow.

\section{LA SOCIEDAD FABIANA Y SU APORTACIÓN AL MOVIMIENTO MUNICIPALIZADOR}

\subsection{Breve historia de la Sociedad fabiana}

Las lamentables condiciones de numerosos trabajadores en la década de los ochenta del siglo XIX, así como el hecho de que solo unos pocos privilegiados gozaran de unas mínimas condiciones de vida fueron uno de los principales estímulos para la fundación de la Sociedad Fabiana (Fabian Society).

Durante las dos últimas décadas del siglo XIX algunas de las principales bases que habían guiado la economía y la política social victoriana empezaron a ser cuestionadas, coincidiendo con un periodo de moderación del crecimiento económico y de huelgas

54 J. Gascón y Marín, Municipalización de servicios públicos, cit., pp. 223-226; A. Shaw, "The municipal government in Great Britain”, cit., p. 228; R. Boverat, Le socialisme municipal en Anglaterre..., cit., pp. 310-316.

55 J. Gascón y Marín, Municipalización de servicios públicos, cit., pp. 226-227; R. Boverat, Le socialisme municipal en Anglaterre..., cit., pp. 351-353. Señalaba este autor que ya desde los primeros meses de prestación del servicio, el Municipio constató una clara disminución de la mortalidad infantil, si bien también tuvo que admitir un cierto déficit del servicio, aunque no excesivamente elevado. Boverat matizaba que, en la mayoría de los ejercicios, simplemente solían compensarse gastos con ingresos. 
periódicas que conllevaron desempleo y disturbios ${ }^{56}$. De hecho, en las décadas centrales del siglo XIX, la sociedad inglesa pasó de la prosperidad victoriana a una situación de preocupación por la transformación de la economía y por los problemas y el descontento social que culminaría en la "Gran Depresión” de mediados de los setenta.

En un contexto en el que resurgían los conflictos sociales que habían aquejado Inglaterra a lo largo de las décadas de los treinta y los cuarenta, los fabianos "formaron parte de un fermento de pensamiento social y político que empezó a plantear de nuevo las bases éticas y la efectividad, tanto del capitalismo como del liberalismo, para hacer frente a las necesidades espirituales y físicas de la sociedad"57.

En este sentido, ha señalado Stevenson que los fabianos se insertaban en el conjunto de aquellos grupos de pensadores que abandonaron definitivamente una posición -predominante en los años del "gran equilibrio", entre 1851 y 1867- en la que la preocupación por los asuntos sociales se traducía en medidas puramente filantrópicas, pero renunciando a adoptar medidas sistemáticas o estatalmente patrocinadas, consideradas entonces propias de un Estado benefactor que aún era rechazado. Por el contrario, sobre todo a partir de los setenta, hubo una toma de conciencia de que la condición de buena parte de la población obrera estaba fuera del alcance de los presupuestos del liberalismo victoriano, reconociéndose que el problema de los pobres había llegado a un punto en el que solo podía ser efectiva la acción estatal, atacando la fe victoriana en la eficacia del individualismo y del principio del "ayúdate a ti mismo" (Self Help) $)^{58}$.

Así, en enero de 1884, algunos miembros de la hermandad New Life, un grupo fundado en octubre de 1883 para el debate de cuestiones morales, decidieron ampliar sus discusiones al examen de problemas económicos, fundando así la Sociedad Fabiana -que debe su nombre a un antiguo general romano Quintus Fabius Maximus (conocido como Cunctator) que luchó contra Aníbal- con el primordial objeto de estudiar las condiciones de la pobreza y buscar soluciones que permitieran su erradicación ${ }^{59}$. A ella se unió, casi inmediatamente, un joven periodista llamado Bernard

56 J. Stevenson, “De la filantropía al fabianismo”, cit., p. 25.

57 J. Stevenson, “De la filantropía al fabianismo”, cit., p. 26.

58 J. Stevenson, “De la filantropía al fabianismo”, cit., pp. 27-37. De igual modo, Cole ha afirmado que ninguna persona mínimamente razonable que observara las duras condiciones de vida de la sociedad victoriana tardía podría dudar que la única solución razonable era el socialismo en el sentido fabiano, esto es, y entre otras cuestiones, la creación de empresas públicas estatales y sobre todo municipales. Cfr. M. Cole, “Beatrice and Sydney Webb”, en M. Katanka (ed.), Radicals, reformers and Socialists, Fabian biographical Series, Charles Knight Ltd., London, 1973, pp. 202-259. Sobre el concepto fabiano de socialismo también G. B. Shaw, "What socialism will be like" (lecturer delivered before the Hammersmith Socialist Society at William Morris's Kelmscott House, Hammersmith, 12 July 1896, The Labour Leader, 19 December 1896), en G. B. Shaw, Platform and Pulpit, Rupert HARD-DAVIS (ed.), London, 1962, pp. 26 y 27.

59 J. F. Milburn, "The Fabian Society and the british labour Party", The Western Political Quarterly, 11: 2, 1958, June, p. 319. Sobre los orígenes de la sociedad fabiana y de la hermandad New Life, N. Mackenzie, "Percival Chubb and the founding of the Fabian Society", Victorian Studies, 23:1, otoño 1917, pp. 29-55. Son imprescindibles los trabajos de A. M. MacBriar, Fabian socialism and english politics 1884-1918, Cambrid- 
Shaw, quien a su vez incorporaría al grupo a su íntimo amigo Sidney Webb. Shaw y Webb, junto con Sydney Olivier y Graham Wallas completaban el grupo que luego sería conocido como los "Cuatro Grandes" del movimiento fabiano, infundiendo a la reducida sociedad de menos de cien miembros una impronta que apuntaba, si no directamente al socialismo, al menos sí en una dirección socialista ${ }^{60}$.

Debe señalarse que, desde sus orígenes, la sociedad fabiana se basó en la libre discusión entre todos sus miembros, alejada en este sentido de una línea ideológica ortodoxa que debiera seguirse obligatoriamente. Así, las opiniones discrepantes de la mayoría no solo se admitían, sino que eran bien vistas, fomentadas y aplaudidas, pues se consideraba que con ellas se fortalecía el espíritu fabiano. No obstante, no puede negarse el papel y la importancia que adquirió, en el seno de este grupo de intelectuales, la figura de Sydney Webb, quien ejerció un papel de primus inter pares hasta el punto de que se ha dicho que el fabianismo, tal y como se expresó y manifestó durante este periodo, hubiera sido impensable sin su presencia y sus aportaciones ${ }^{61}$.

Así las cosas, lo cierto es que en abril de 1884 el pequeño grupo fabiano ordenó la impresión de dos mil copias del primer Fabian Tract, titulado Why are the many Poor?, del que se vendieron en los años sucesivos más de cien mil ejemplares. Poco después, Webb leería en una reunión de la sociedad su primer escrito, The Way Out, y ya en 1885 se publicaría el Tratado número cinco, Facts for Socialism, que, junto con el Tratado octavo, Facts for Londoners, de 1889, marcaría la línea ideológica a la que los fabianos se verían asociados desde entonces ${ }^{62}$.

Tras algunas discusiones, la sociedad aceptó un programa común en las denominadas Basis, las cuales, salvo algunas modificaciones menores, se mantuvieron prácticamente intactas hasta 1939.

El socialismo fabiano, tal y como se expresó originariamente en 1887, proponía el uso de las instituciones, los partidos políticos y toda la maquinaria parlamentaria con el objetivo de realizar reformas prácticas en el ámbito político y administrativo. Estas reformas se diseñaban, en última instancia, con la pretensión de transformar gradualmente (gradualism) el capitalismo en una forma de Estado del bienestar que, para asegurar un adecuado nivel de vida a todos los ciudadanos, consideraba necesario tener la propiedad y el control de los medios de producción ${ }^{63}$.

\footnotetext{
ge University Press, Cambridge, 1966, pp. 1-28, cuyo capítulo I (The origins of the Fabian Society and of its socialist doctrine) está dedicado exclusivamente a la formación y primeros momentos de la sociedad fabiana y de E. Pease, The history of the Fabian Society, Frank Cass \& Co, London, 1963, pp. 28-38, quien dedica su capítulo II (The foundations of the Society) a los orígenes y la aparición de la sociedad.

60 J. Stevenson, “De la filantropía al fabianismo”, cit., p. 26; E. Reichel, Der Sozialismus der Fabier, Verlag Lambert Schneider, Heidelberg, 1947, pp. 54 y 55.

61 E. Reichel, Der Sozialismus der Fabier, cit., pp. 36 y 37.

62 M. Cole, "Beatrice and Sydney Webb", cit., p. 210.

63 J. Stevenson, "De la filantropía al fabianismo", cit., p. 39; J. F. Milburn, "The Fabian Society and the british labour Party”, cit., p. 320; A. M. MacBriar, Fabian socialism and english politics..., cit., p. 111. No
} 
Desde mediados de los noventa, los fabianos utilizaron el slogan The National Minimum para describir su propuesta política y social, que consideraban como una mera extensión de una larga serie de medidas interventoras de los poderes públicos que ya se habrían iniciado con la regulación de las condiciones fabriles y la salud pública. Gradualmente se estaba reconociendo -y exigiendo- que los poderes públicos admitieran su responsabilidad para preservar determinados estándares mínimos, por debajo de los cuales ningún ciudadano pudiera encontrarse: jornada mínima de 8 horas laborales, salarios dignos, mejoras en las condiciones de habitación, reforma de la ley de pobres, facilidades educativas, etc. Esta doctrina del mínimo existencial fue acuñada por los Webb en su obra Industrial Democracy y, aunque los fabianos exigían estas reformas desde una perspectiva socialista, lo cierto es que muchas de ellas se extendían más allá de las filas socialistas, como luego veremos con detalle ${ }^{64}$.

Los instrumentos y métodos propuestos a tal fin eran, principalmente, la extensión de la democracia y la mejora de los mecanismos de control democrático del Gobierno, unos impuestos razonables y equitativos, así como la nacionalización de los ferrocarriles y de las minas de carbón, y la municipalización de los servicios municipa$l^{e} s^{65}$, en la que se centraron especialmente sobre todo durante la década de los noventa del siglo XIX, probablemente por la situación de los servicios municipales en la ciudad de Londres, su principal centro de operaciones ${ }^{66}$.

Entre 1884 y 1889 la sociedad fabiana aumentó su número de socios desde 31 hasta 1886, configurándose ocho grupos en el área de Londres. Cuando a partir de 1900 ampliaron su actividad también al ámbito provincial -los Condados (County)- se incrementó notablemente el número de miembros a nivel nacional, superando los 2.000 en 1908, ritmo creciente que se mantuvo hasta 1916, fecha en la que la sociedad fabiana iniciará una decadencia que le llevará al borde de la desaparición ${ }^{67}$.

obstante, los fabianos insinuaban que un socialismo completo en el sentido de una sociedad en la que todas y cada una de las industrias estuviera socializada no sería realmente factible ni deseable, poniendo de relieve, a partir del Tract 70, que incluso en una sociedad mayoritariamente socialista una pequeña proporción de empresas privadas podría ser útil, contribuyendo a la innovación tecnológica y al progreso, por lo que debería permitirse su existencia.

64 A. M. MacBriar, Fabian socialism and english politics..., cit., pp. 107 y 108.

65 A. M. MacBriar, Fabian socialism and english politics..., cit., pp. 25, 26 y 110; T. Willis, "Contributing to a real socialist commonwealth: municipal socialism and health care...", cit., p. 101; J. F. Milburn, "The Fabian Society and the british labour Party", cit., p. 320. Además, los fabianos, mayoritariamente pertenecientes a la clase media, aspiraban a educar a todas las clases sociales en la vía del socialismo, a través de lecturas y publicaciones.

66 U. Kühl, “Le débat sur le socialisme municipal en Allemagne avant 1914 et la municipalisation de l'électricité", en U. Kühl, Der Munizipalsozialismus in Europa/ Le socialisme municipal en Europe, Parischen Historische Studien, Oldenbourg Verlag München, 2001, p. 84, quien ponía de relieve el estado en el que entonces se hallaba el Municipio de Londres, absolutamente subdesarrollado y necesitado de profundas reformas, sobre todo en comparación con las otras grandes ciudades inglesas o escocesas. En sentido similar también E. Reichel, Der Sozialismus der Fabier, cit., p. 91, añadiendo que esta preocupación particular por los problemas londinenses era especialmente intensa en Sydney Webb. Para la situación detallada de la ciudad de Londres en este periodo, nos remitimos al siguiente epígrafe.

67 J. F. Milburn, "The Fabian Society and the british labour Party", cit., pp. 320 y 321. En efecto, durante los años veinte el interés por la Sociedad fabiana decayó debido a numerosos factores. Hay que 
En sus primeras décadas de existencia la sociedad fabiana consideró dos posibles alternativas de acción política, que estuvieron debatiéndose en el seno de la organización hasta 1918.

Originariamente, en un tiempo en que aún no existía un Labour Party, los fabianos recurrieron a la estrategia de expandir las ideas fabianas a todos los partidos, líderes y gobiernos oficiales que fueran recepticios a ellas, trabajando transversalmente para la reforma (política conocida como permeation) ${ }^{68}$. Así, de algún modo pretendían que los liberales y los conservadores llevaran a cabo las ideas socialistas sin reconocer sus implicaciones (socialistas), siendo buen ejemplo de ello la decisión de Sidney Webb de trabajar con los conservadores en la reforma educativa entre los años noventa y principios del siglo $X X^{69}$. Esta política de impregnación fue la oficialmente establecida en las Basis.

Como ha señalado Cole, una de las principales estudiosas de la sociedad fabiana, la técnica de la impregnación o permeation parecía ser, cuando menos originariamente, la más adecuada a las aspiraciones fabianas. En efecto, los fabianos, conscientes de su condición minoritaria, no llegaron a pensar nunca en la posibilidad real de un "gobierno fabiano" ni, de hecho, originariamente tampoco en la de un "gobierno laborista", teniendo en cuenta que antes de 1900 no había ningún partido que respondiera a semejante denominación, e incluso cuando lo hubo, al menos hasta 1914 llamó escasamente la atención de los Webb, cuyas directrices ideológicas, a pesar de la existencia de corrientes internas en la sociedad, dominaron el fabianismo entre 1890 y los años treinta. La idea de los fabianos era, por lo tanto, la de intentar convertir a futuros ministros y otras personalidades clave para el movimiento fabiano (independientemente de que fueran tories, liberales o anarquistas: “todos eran potencialmente permeables”), así como persuadir a grupos, comités, partidos o consejos para que adoptaran principios del programa socialista ${ }^{70}$.

Sin embargo, pronto iban a aparecer los conflictos de estrategia. Así, en 1887 dos fabianos, Annie Besant y Hubert Bland esponsorizaron la Fabian Parliamentary League -que duró poco- en la que, además de la política de la impregnación, que no rechazaban, recomendaban la futura formación de un partido socialista71. En los no-

tener presente, sobre todo, que buena parte del programa originario de reformas, incluyendo las municipalizaciones, se había cumplido, y la sociedad fue incapaz de formular un nuevo programa suficientemente atractivo y capaz de generar el interés de la opinión pública en relación con sus actividades, a pesar de que llevaron a cabo estudios tanto de régimen local como sobre problemas nacionales.

68 J. F. Milburn, "The Fabian Society and the british labour Party", cit., p. 324; A. M. MacBriar, Fabian socialism and english politics..., cit., p. 95.

69 J. Stevenson, "De la filantropía al fabianismo", cit., p. 40. Sobre la reforma educativa en el Condado de Londres, en la que participó Webb, véase A. M. MacBriar, Fabian socialism and english politics..., cit., pp. 206-222 y E. Reichel, Der Sozialismus der Fabier, cit., pp. 94-97, poniendo de relieve la amistad personal que unía al por entonces Primer ministro (y conservador) Balfour y a su Ministro de educación Gorst con el propio Webb, lo que sin dudo tuvo que facilitar notablemente el trabajo conjunto y la posible influencia de este último sobre aquellos.

70 M. Cole, “Beatrice and Sydney Webb”, cit., pp. 219 y 220.

71 J. F. Milburn, “The Fabian Society and the british labour Party”, cit., p. 324 y 325. Véanse también las consideraciones que realizaba Shaw en el Tratado $n^{\circ} 41$, The Fabian Society: its early history, the fabian 
venta era ya claro que miembros como Ramsay Macdonald trataban de usar la sociedad para, directamente, "fabricar socialistas", en tanto que los Webb veían su papel como el de "hacer que las personas pensaran en socialista"72.

Además, con cierta frecuencia se oían en el seno de la sociedad fabiana voces que propugnaban la formación de un partido político. El propio Bernard Shaw recomendó, en 1893, la formación de un partido laborista, y cuando el Independent Labour Party se creó ese mismo año, Shaw, como delegado fabiano, estableció que la sociedad cooperaría con el partido aunque no se uniría a él73. En 1907 un grupo de fabianos capitaneados por H. G. Wells y H. H. Slesser, manifestándose claramente contra la política de la impregnación, defendieron que la sociedad consolidara sus esfuerzos políticos en la formación de un partido político socialista ${ }^{74}$. Su propuesta no tuvo éxito, pero el cambio en la acción política fabiana desde la permeabilidad hacia una futura afiliación al partido laborista -creado en 1906- se hizo evidente a partir de 1913. En este periodo Webb, que junto a su mujer se había desilusionado con la opción de la permeabilidad, empezó a participar en las acciones y actividades del partido laborista, y en 1916 se convirtió en miembro de la ejecutiva nacional del mismo. Lo cierto es que a partir de 1918 la sociedad fabiana apoyaba de forma casi exclusiva a los candidatos parlamentarios laboristas ${ }^{75}$.

Sin embargo, fue en 1919, una vez que el partido hubiera adoptado un nuevo programa político, el Labour and the New Social Order en cuya redacción participó Webb, cuando la sociedad reconoció abiertamente su apoyo al partido, consumándose la incorporación del socialismo fabiano al partido laborista, en cuyo nuevo programa eran visibles ciertos elementos de la propaganda fabiana como la exigencia de eficiencia nacional o el socialismo democrático ${ }^{76}$. Ahora bien, la sociedad abandonó la política de la permeation respecto de los partidos políticos, pero no para otros grupos sociales, respecto de los cuales la permeabilidad continuó siendo defendida y aceptada en la

Society publications, 1892, reprint 1909, pp. 10-15, incluyendo el manifiesto fundacional de la Fabian Parliamentary League.

72 J. Stevenson, "De la filantropía al fabianismo", cit., p. 40.

73 J. F. Milburn, "The Fabian Society and the british labour Party", cit., p. 325. Una política similar fue seguida con el Labour Representation Comittee entre 1900 y 1906 y, posteriormente, con el Labour Party entre 1906 y 1919, tal y como explicamos en texto. La influencia de la sociedad fabiana sobre el Independent Labour Party la analiza con gran detalle A. M. MacBriar, Fabian socialism and english politics..., cit., pp. 280-305, especialmente pp. 280-286 y 290-305.

74 J. F. Milburn, "The Fabian Society and the british labour Party”, cit., p. 325.

75 Entre 1906 y 1918 la sociedad fabiana estuvo representada en todas las conferencias del partido laborista, pero solo a partir de 1919 se decidió por apoyar a este partido con exclusión de los otros. Hasta ese momento, la mayor parte de las actividades de la sociedad con respecto al partido laborista se habían limitado al establecimiento, en 1908, de un fondo para financiar candidatos.. J. F. Milburn, "The Fabian Society and the british labour Party", cit., p. 328, así como también M. Cole, "Beatrice and Sydney Webb”, cit., p. 223 y A. M. MacBriar, Fabian socialism and english politics..., cit., pp. 312-315, quien señalaba que las relaciones entre los fabianos y el partido laborista, durante este periodo, estuvieron presididas por una benevolent passivity.

76 J. F. Milburn, "The Fabian Society and the british labour Party”, cit., p. 328; E. Reichel, Der Sozialismus der Fabier, cit., pp. 90 y 91. 
revisión de las Basis en 1919: "The Society is a constituent of the Labour Party and of the International Socialist Congress; but it takes part freely in all constitucional movements, social, economic and political, which can be guided towards its own objects"77.

\subsection{La Sociedad fabiana y el socialismo municipal}

Uno de los principales problemas con el que nos encontramos al estudiar la corriente ideológica fabiana es la confusión terminológica que el término "socialismo municipal" conllevaba en esta época, y que en cierto modo se ha venido arrastrando hasta la actualidad. Como señalara Kühl, hacia finales del siglo XIX la expresión "socialismo municipal" estaba de moda en todas las ciudades europeas: para unos, era la promesa futura de un nuevo orden socialista o, cuando menos, de un marco de vida mejor y más social; para otros, una amenaza directa al orden social burgués y al capitalismo liberal, y el peligro de que "la sombra del socialismo, que hasta ahora se había mostrado como una amenaza a nivel nacional e incluso internacional, se colara por la puerta de servicio, en los Municipios"78. Asimismo, incorporaba también una noción más neutra, relativa al City goverment o gobierno de la ciudad.

En todo caso, el concepto de socialismo municipal se considera, comúnmente, como una creación de la London Fabian Society, si bien el término fue popularizado no solo por los fabianos y los socialistas en general, sino también por los conservadores y los moderados, que querían movilizar a sus electores ${ }^{79}$. Lo cierto es que la expresión se popularizó entre todos los sectores sociales, y logró cuajar en la opinión pública con tanta intensidad que ha llegado hasta nosotros.

Los fabianos, según se ha dicho, propugnaban un socialismo reformista: impuestos razonables y equitativos; la nacionalización inmediata de las minas, ferrocarriles, canales, telégrafos o teléfonos; la municipalización inmediata de los servicios de agua, gas, luz eléctrica, mercados, tranvías, ómnibus, montepíos, barcos a vapor que surcaban los lagos y ríos y de todos los monopolios locales; la puesta a cargo de las autoridades locales de las empresas de fabricación y venta al detalle de tabaco, bebidas alcohólicas, carbón, pan, leche y otros artículos de primera necesidad, así como la construcción de viviendas para obreros ${ }^{80}$.

Y ciertamente, la actividad de la sociedad fabiana en el ámbito municipal fue muy intensa durante la última década del siglo XIX y la primera del XX, desde la publicación

77 J. F. Milburn, "The Fabian Society and the british labour Party”, cit., p. 326; A. M. MacBriar, Fabian socialism and english politics..., cit., pp. 343-345.

78 U. Kühl, "Einleitung”, en U. Kühl, Der Munizipalsozialismus in Europa/ Le socialisme municipal en Europe, Parischen Historische Studien, Oldenbourg Verlag München, 2001, p. 15; en el mismo sentido P. Dogliani, “Il dibattito sulla municipalizzazione in Europa...", cit., p. 230.

79 A. M. MacBriar, Fabian socialism and english politics..., cit., p. 195.

80 N. Muratti, Municipalización de los servicios públicos. Estudio económico, financiero, político, jurídico y social, Librería jurídica, Buenos Aires, 1928, p. 203. 
del Fabian Municipal Programme en 1891, a la que siguió la de otras propuestas en los conocidos opúsculos Fabian Tracts (por ejemplo, el ya mencionado Facts for Londoners), hasta una última propuesta sobre Municipal Trading en 1908. Por otra parte, Beatrice y Sidney Webb elaboraron el informe de la minoría (minority report) para la Comisión parlamentaria que preparaba una Ley sobre pobres (Poor Law), a partir del cual desarrollaron algo parecido a un incipiente Welfare State que apoyaron, decididamente, sobre la reforma local ${ }^{81}$. Sin olvidar, tampoco, la coalición progresista que gobernaba el reconstituido London County Council a partir de 1889, el conocido manifiesto aparecido en el Daily Mail en 1896 (titulado The Gas and Water Socialism) o el hecho de que fueron los fabianos los primeros que propusieron a la Segunda Internacional de Londres, en 1896, la nacionalización y la municipalización de la industria, mediante la moción presentada por Sydney Webb Some facts and considerations about municipal socialism, propuesta muy bien acogida en ambientes socialistas, incluyendo los reformistas españoles ${ }^{82}$.

Ahora bien, es importante señalar, desde un primer momento, que esta municipalización de servicios propugnada por el movimiento fabiano y, con carácter general, por todas las corrientes socialistas, en modo alguno era un fenómeno nuevo que hubiera sido alumbrado por pensadores fabianos; tampoco podía considerarse una exigencia política que se limitara al campo socialista. En efecto, tal y como ya vimos, la propiedad municipal de los servicios de agua, las fábricas de gas o los tranvías existía desde hacía tiempo, antes de que los fabianos comenzaran con sus reivindicaciones y empezaran a surgir y a desarrollarse los partidos socialistas ${ }^{83}$.

Sin duda, los socialistas, y más aún los colectivistas, vieron en la municipalización de servicios públicos un camino que podría conducir a la socialización de los medios de producción y consumo. Pero el movimiento municipalizador, debe insistirse, precedió cronológicamente a la expansión de la propaganda socialista, y además se inició en Inglaterra, uno de los países más reacios al socialismo: de hecho, una de las primeras ciudades inglesas que emprendió la senda del municipalismo fue Manchester, que alumbró también el individualismo y los principios del laissez-faire ${ }^{84}$. Sin olvidar el caso particular de Birmingham (que inspiró precisamente la expresión gas and water socialism), ciudad en la que durante la década de los setenta del siglo XIX florecieron los más variados servicios gestionados por el propio Municipio, dirigido por el empresario y liberal Joseph Chamberlain.

81 P. Dogliani, "La sinistra europea alle origini del movimento comunale internazionale”, en P. Dogliani / O. Gaspari (a cura di), L'Europa dei comuni dalla fine dell'Ottocento al secondo dopoguerra, DonzeIli, Roma, 2003, p. 174; E. Reichel, Der Sozialismus der Fabier, cit., pp. 85 y 86.

82 G. Zucconi, "Il Municipio, nuevo soggetto urbanistico: la svolta di fine Ottocento", en Dogliani, P. / Gaspari, O., (a cura di), L'Europa dei comuni dalla fine dell'Ottocento al secondo dopoguerra, Donzelli, Roma, 2003, pp. 63-75; p. 69; P. Dogliani, “La sinistra europea alle origini del movimento...”, cit., p. 174 y P. Dogliani, “Il dibattito sulla municipalizzazione in Europa...”, cit., p. 224.

83 U. Kühl, “Le débat sur le socialisme municipal en Allemagne...”, cit., p. 84 ; E. Pease, The History of Fabian Society, cit., p. 81.

84 N. Muratti, Municipalización de los servicios públicos..., cit., p. 201. 
No hay duda de que este socialismo del gas y del agua no cabe vincularlo con el socialismo en el que la propiedad y el control de los medios de producción e intercambio son enteramente públicos. Más bien se trató de unos líderes paternalistas de la burguesía local que, habiendo llegado al gobierno municipal, consolidaron su poder y aplicaron mejoras de carácter cívico y social, buscando también la obtención de beneficios para, con ello, reducir los impuestos locales, por lo que el término más correcto sería, en todo caso, el de Municipal Trading y no socialismo municipal ${ }^{85}$.

En buena medida cabe concluir que la municipalización surgió, cuando menos originariamente, no como resultado o aplicación de un principio socialista, sino por la influencia de preocupaciones de orden puramente práctico, por "simple oportunismo práctico" 86 . Por lo tanto, si bien la corriente de ideas favorables a la municipalización que suscitó la Fabian Society permitió acrecentar ese movimiento económicosocial en las ciudades inglesas, no lo hizo nacer porque, como ha señalado Muratti, "la acción concreta, meticulosa, penetrante, realista y prácticamente ilimitada de las autoridades inglesas después del siglo XVIII reposa en el espíritu práctico del pueblo inglés y en la ampliación normal de las funciones municipales, independiente de todo interés particular" 87 .

En este sentido, tal vez sea preciso diferenciar entre un socialismo municipal con claros tintes ideológicos -como pudo ser el francés o el italiano- y el comúnmente llamando "socialismo del gas y del agua", propio del mundo anglosajón y de los países germánicos, y en el que las connotaciones ideológicas tenían un bajo relieve pues su objetivo principal era eminentemente práctico. Sin duda, en países como Francia e Italia, la paralela ampliación del sufragio y el consiguiente acceso de los partidos socialistas al poder local contribuyeron a que los procesos municipalizadores adquirieran un aspecto ideológico y se convirtieran, por ello, en principal objetivo de las hostilidades liberales ${ }^{88}$.

Sin embargo, no puede negarse que la importancia creciente que adquirió el movimiento municipalizador a partir de los años ochenta en Inglaterra se debió en buena medida a la propaganda sistemática de las asociaciones socialistas, entre las que se contaba, de forma muy especial -y además de la Social Democratic Federation, fundada en 1881 y el Independent Labour Party, fundado en 1893- la Fabian Society.

85 T. Willis, "Contributing to a real socialist commonwealth: municipal socialism and health care...", cit., p. 102.

86 N. Muratti, Municipalización de los servicios públicos..., cit., pp. 201 y 202.

87 N. Muratti, Municipalización de los servicios públicos..., cit., pp. 203 y 204; en un sentido similar, P. Dogliani, “Il dibattito sulla municipalizzazione in Europa...", cit., p. 227, siguiendo al economista italiano de orientación socialista (sobre todo en sus primeros años) Attilio Cabiati.

88 De hecho, con carácter general fueron los liberales los primeros en utilizar, en sentido peyorativo, el término "socialismo municipal" incluso antes de que el estandarte de la municipalización fuera acogido por la izquierda municipal. Cfr. J. Lorcin, "Le socialisme municipal en France. Le cas de Saint-Étienne; modèle ou exception?", en U. Kühl, Der Munizipalsozialismus in Europa/ Le socialisme municipal en Europe, Parischen Historische Studien, Oldenbourg Verlag München, 2001, pp. 61-78, p. 61. 
En este sentido, la propaganda que el programa y el ideario socialista recibieron de los fabianos no debe infravalorarse: así, la publicación del ya mencionado Facts for Londonders, un escrito lleno de datos, estadísticas y proposiciones de reforma sobre la base del programa fabiano, fue calificado por los propios fabianos como "the raw material of Municipal Socialism, and from this time forth the Society recognised that the municipalisation of monopolies was a genuine part of the Socialist programme" ${ }^{89}$. Por otra parte, el denominado London Programme, publicado por Sidney Webb en 1891, se convirtió en el programa base del socialismo municipal, mientras el ya renovado County Council de Londres comenzaba, desde 1888, a debatir políticamente la municipalización ${ }^{90}$.

Por todo ello, sí puede afirmarse que a la Sociedad fabiana corresponde el mérito de haber puesto de manifiesto las condiciones económicas que conducían a la municipalización ${ }^{91}$ : una producción necesariamente monopolística o para la que se requería el ejercicio de poderes excepcionales sobre los individuos o la propiedad pública, la posibilidad de que la autoridad pública pudiera producir convenientemente sin recurrir a intermediarios, o una centralización de la producción total de un servicio que reportase ventajas para el público. En todos estos casos, el socialismo municipal se reputaba superior y preferible a la empresa capitalista, individual o colectiva. Dicho en otras palabras, que tomamos del profesor García de Enterría: los fabianos prestaron al movimiento municipalizador la formulación teórica de la que hasta entonces carecía, alumbrando la idea de una Administración prestadora de servicios en un entorno político y jurídico que la negaba dogmáticamente ${ }^{92}$.

En definitiva, igual que en Alemania el debate en torno a la necesidad de las reformas sociales y cambios en las funciones de los poderes públicos se realizó principalmente en el seno de la Verein für Sozialpolitik (un grupo de economistas y sociólogos que también recibirían el apelativo de "socialistas de cátedra") a partir de la década de 1870, un grupo de intelectuales ingleses, aglutinados en torno a la London Fabian Society, dieron al socialismo municipal una nueva vitalidad, al convertirlo en parte esencial de su programa político. La extensión de la actividad económica de los Municipios constituyó el pilar fundamental de su aspirado nuevo orden social y, al mismo tiempo, allanó el camino hacia él93.

89 E. Pease, The History of Fabian Society, cit., p. 81.

90 E. Pease, The History of Fabian Society, cit., p. 81. Señala este autor que mientras en las ciudades de provincia la municipalización se contemplaba como una cuestión formal y empresarial, sin contenido político-social, en Londres se convirtió en auténtico campo de batalla político. Asimismo, y precisamente por ello, no queda claro, en su opinión, si el desarrollo del fabianismo y el debate que este generó en torno a la ciudad de Londres y a sus servicios sirvió realmente para acelerar el proceso de municipalización o, más bien, ralentizó su desarrollo al verse envuelto en una dura batalla político-ideológica.

91 N, Muratti, Municipalización de los servicios públicos..., cit., pp. 203 y 204.

92 E. GARCíA de Enterría, “La actividad industrial y mercantil...", cit., pp. 100-104, señalando que los británicos tuvieron que construir originariamente la idea de la Administración prestadora sobre el Municipio, pues era la estructura administrativa principalmente existente, tal y como se indicó en texto al

$40 \quad$ principio de este trabajo.
$93 \quad$ U. Kühl, "Einleitung“, cit., p. 16. 


\subsection{La sociedad fabiana y la reforma municipal londinense}

Como hemos visto, la sociedad fabiana fue la principal propagandista de las reformas que llevaron el nombre de "socialismo municipal" durante al menos dos décadas, los años noventa y la primera década del siglo XX. Sydney Webb, probablemente su figura más influyente, Ilamó tempranamente la atención de sus colegas sobre la importancia de la política local (recuérdense los textos Facts for Londoners y The London Programme) y sobre el nuevo campo de batalla que esta abría para la propaganda y la actividad fabiana.

Como resultado de lo anterior, se ha tendido, desde un primer momento, a sobrevalorar la originalidad de las propuestas de Webb para la reforma londinense, cuando muchas de ellas estaban ya incluidas en los programas y propuestas liberales y radicales. En realidad, el movimiento para la reforma londinense tenía una historia muy anterior al momento en que los fabianos decidieron unirse a él, una historia que comenzó cuando Londres fue excluida de la Municipal Corporations Act de 1835, que había reformado el gobierno municipal de otras ciudades inglesas.

Los motivos que explican esta exclusión son varios. Por un lado, hay que señalar que en la base de la nueva normativa se hallaba un informe previo de la Royal Commission, que excluyó, por su complejidad, el estudio sobre la ciudad de Londres, para la cual necesitó dos años adicionales de investigaciones. Si bien cuando se entregó el informe especial los comisionarios concluyeron que no había motivos para no aplicar la Municipal Corporations Act de 1835 a la ciudad de Londres, lo cierto es que la posible reforma ya había entrado en fase de parálisis ${ }^{94}$.

A ello hay que sumarle que la City Corporation, temerosa de que una reforma del gobierno local pudiera hacer disminuir su autoridad, mantuvo una intensa oposición a cualquier atisbo de reforma durante más de cincuenta años. En este sentido, el hecho de que la reforma de 1835 no se aplicara a la ciudad de Londres suponía que no se incorporaban a ella los distritos urbanos que la rodeaban (normalmente bastante pobres), así como que sobre ella tenían autoridad tres Counties: Middlesex (cubriendo la zona al Norte del Támesis y al oeste del río Lee), Surrey (suroeste) y Kent (sudeste). Con el objetivo de que existiera al menos un órgano local de coordinación se aprobó en 1855 la Metropolis Local Management Act, que creaba el Metropolitan Board of Works, compuesto por representantes religiosos y civiles y por miembros de la City.

Sin embargo, el nuevo órgano fue investido con limitados poderes, intentando la City mantenerlo lo más subordinado posible a sus autoridades. Así las cosas, el Metropolitan Board of Works funcionó razonablemente bien para servicios como el alcantarillado o el desagüe de agua, pero poco pudo hacer para satisfacer las deman-

94 A. M. MacBriar, Fabian socialism and english politics..., cit, p. 187 y M. Cuchillo Foix, La reforma del régimen local en Inglaterra..., cit., pp. 80 y 81. 
das de reforma que exigían acabar con una época de anarquía y gobierno de las empresas privadas en Londres 55 .

Como consecuencia de este retraso, las demandas generalizadas de reforma llegaron en los años ochenta, cuando no solo los radicales sino también los conservadores y The Times las apoyaban expresamente. Por ello, como se dijo, cuando los fabianos entraron en escena la cuestión de la reforma había dejado ya de ser una cuestión de partido.

Finalmente, en 1888 la Local Government Act abolió el Metropolitan Board of Works -acosado por múltiples escándalos de corrupción constatados por las investigaciones de la Royal Commission y aireados por la prensa (sobre todo por el Financial Times) - y estableció el London County Council. Además, esta norma tenía como objetivo general el establecimiento de County Councils por toda Inglaterra, por lo que de algún modo se forzaba a sí misma a establecer algunas previsiones expresas para la ciudad de Londres, si no quería perpetuar la división existente en tres Counties, aumentando aún más la confusión en torno al gobierno de la ciudad ${ }^{96}$.

Sin embargo, las nuevas previsiones especiales para Londres estaban lejos de corresponderse con lo exigido por los reformistas radicales, al tratar solo las exigencias más inmediatas. En efecto, con ella se hizo de Londres un County separado, el London County Council (en adelante, LCC) que sustituyó al Metropolitan Board of Works; por lo demás, nada cambió. La City Corporation permaneció intacta, sin hacerse tampoco alteración alguna en las pequeñas autoridades, evitando así el problema de reorganizarlas y establecer su relación formal con el LCC, con la excusa de que se trataba de una regulación general para todas las ciudades inglesas, por lo que un exceso de detalle en las previsiones para Londres sobrecargaría la norma, prometiendo a cambio el Gobierno un Bill detallado para una fecha posterior ${ }^{97}$.

Es en este contexto y en este momento en el que la sociedad fabiana apareció en la escena municipal londinense. ¿Qué relacionó a los fabianos con los reformistas municipales que les habían precedido, y qué aportó el fabianismo como innovación? Los fabianos, al igual que los reformistas londinenses (entre los que se incluían no solo radicales sino también conservadores, y en general un conjunto de administradores públicos de otras ciudades inglesas), caracterizaron su propaganda afirmando que las reformas que propugnaban ya habían sido probadas y habían funcionado en otros lugares, por ejemplo, en muchas ciudades de provincias.

95 A. M. MacBriar, Fabian socialism and english politics..., cit., pp. 188 y 189. En 1867 el Parlamento intentó, sin éxito, reformar la ley para dar cabida a algunas de las demandas exigidas por los reformistas, aumentándose las funciones y poderes del Metropolitan Board of Works (en materia de suministro de agua y gas, o de tranvías) y modificándose su nombre a Municipal Council of London.

96 A. M. MacBriar, Fabian socialism and english politics..., cit., p.190.

97 A. M. MacBriar, Fabian socialism and english politics..., cit., p. 190 y 191. Sobre la reorganización 42 de la ciudad de Londres T. Elorrieta y Artaza, La municipalización de servicios en el Condado de Londres, cit.,
pp. 5-8. 
Así, cuando los fabianos proponían el abastecimiento municipal de gas en Londres, remarcaban especialmente que 170 ciudades inglesas ya poseían sus propios gasómetros; cuando exigían urgentemente la construcción de tranvías municipales, alegaban que 31 ciudades inglesas ya los tenían, y una de ellas, Huddersfield, sin contratista interpuesto; cuando hablaban de mejorar la situación de la vivienda, ponían como ejemplo Liverpool, Greenoch o Glasgow. Asimismo, comparaban la situación de los muelles de Londres durante los ochenta con los de Mersey, Liverpool, Glasgow, Bristol o Dublín, todos ellos en manos públicas, y cuando solicitaban la municipalización de agua en Londres ponían de relieve que ya un gobierno conservador, en 1879, había decidido proceder a la misma, abandonando la propuesta solo por las protestas públicas que siguieron a su decisión de pagar una cuantiosa compensación a los accionistas privados. Lo que pedían, de hecho, al exigir baños, librerías o parques públicos era, simplemente, colocar a Londres entre las ciudades más modernas de Inglaterra, con las mismas ventajas que otras ciudades habían obtenido ya en $1835^{98}$.

Los precursores en la reforma municipal fueron, principalmente, los reformadores liberal-radicales J. F. B. Firth y Joseph Chamberlain ${ }^{99}$. Firth se anticipó a los fabianos en exigir, por ejemplo, que la autoridad central londinense adquiriera los activos de las compañías de agua y gas, y tuviera el control de los mercados y tranvías, considerando incluso su adquisición, como habían hecho otras ciudades (así lo expresó claramente en su panfleto The Gas Supply in London, de 1874). El único servicio sobre el que Firth no hablaba y los fabianos sí era el de los muelles, pero ello se debía a que el interés por su municipalización surgió a raíz de las agitaciones que al respecto tuvieron lugar a finales de los ochenta ${ }^{100}$.

Lo cierto es que, en numerosas sugerencias prácticas en materia de propiedad y administración municipal, o de gestión de servicios municipales esenciales, la posición fabiana no difería excesivamente de la de los liberales. Tampoco de la de los conservadores, que dado el retraso de Londres en materia local, estaban deseosos de aplicar, cuando menos, algunas de las principales reformas propuestas en The London Programme. El mismo Webb había señalado, respecto de este texto, que estaba hecho, precisamente, para superar las diferencias políti-

98 A. M. MacBriar, Fabian socialism and english politics..., cit., pp. 191 y 192.

99 Por otra parte, Firth y Chamberlain discrepaban sobre si debía instaurarse para la ciudad un sistema centralizado o descentralizado. El primero postulaba dejar a la "metrópolis" en manos de una autoridad central con amplios poderes, a la que se someterían estrictamente los diversos distritos. Por el contrario, Chamberlain, partiendo de su experiencia práctica como alcalde de Birmingham, y entendiendo que las dimensiones de esta última eran las adecuadas para la administración local, consideraba que lo mejor era dividir Londres en varias Cities de tamaño similar, "federándolas" para intereses comunes en torno a una autoridad central. Webb, y con él los fabianos, adoptaron una posición intermedia, si bien Webb fue modificando con el tiempo su posición. Así, cuando escribió Facts for Londoners proponía pequeñas autoridades bajo la supervisión y control del London County Council, mientras que en el London Programme apostaba por District Councils de autoridad independiente, que podrían imponer impuestos y otorgar fondos autónomamente. A. M. MacBriar, Fabian socialism and english politics..., cit., p. 193.

100 A. M. MacBriar, Fabian socialism and english politics..., cit., pp. 192 у 193. 
cas entre liberales y conservadores, apelando al apoyo de todos en beneficio de los ciudadanos ${ }^{101}$.

Así las cosas, y teniendo en consideración que inicialmente (en su Facts for Londonders) los fabianos limitaron sus demandas a ciertos servicios que consideraron esenciales (agua, gas, tranvías, puertos, mercados, lavaderos o cementerios), el acuerdo fue prácticamente total, tanto con un sector de los moderados -que a lo sumo discutían la rapidez con la que debían municipalizarse los servicios en cuestióncomo con los progresistas y liberales londinenses, que ya hacía tiempo que defendían y habían aceptado que estos servicios se pusieran bajo el control del London County Council.

En este sentido, las cifras hablan por sí solas: en el primer LCC, elegido en 1888, de un total de 118, no menos de 70 se manifestaron a favor de municipalizar las ocho compañías privadas suministradoras de agua potable, incluyendo entre ellos a numerosos moderados; a favor de la municipalización de los tranvías urbanos se manifestaron las dos terceras partes del consistorio londinense, y en relación con el abastecimiento de gas, de 73 opiniones contrastadas en el LCC, 65 votaron a favor y solo 8 en contra. Todo ello tuvo lugar durante el primer mandato del LCC, en el que no hubo representación fabiana alguna en el mismo, puesto que solo a partir de las segundas elecciones locales y del segundo LCC, elegido en 1892, los fabianos pasaron a formar parte de los representantes políticos electos ${ }^{102}$.

Sin embargo, sí había una línea de demarcación que separaba a los fabianos de los radicales y liberales. Ciertamente, no tan evidente como podría suponerse, puesto que hacía referencia más bien a los objetivos últimos, y no tanto a las exigencias inmediatas. En este sentido, era evidente que los fabianos pensaban primariamente como socialistas. Así, tal vez con un exceso de optimismo -ocasionado por la rapidez con que se dieron algunos avances, a finales del XIX, en la ciudad de Londres- creyeron que estas primeras medidas municipalizadoras llevarían gradualmente a otras más profundas de orientación socialista, basadas en la ampliación de la propiedad pública, sin percatarse de que, muy posiblemente, la facilidad con que se tomaron y realizaron estos primeros pasos en Londres era debida al retraso que acumulaba res-

101 A. M. MacBriar, Fabian socialism and english politics..., cit., p. 197. En relación con esta cuestión, Elorrieta y Artaza hablaba del “espíritu municipal inglés" esto es, de la preocupación inglesa por los asuntos municipales, que llevó a que, en Londres, liberales y conservadores actuasen casi al margen de las políticas nacionales, discutiendo fundamentalmente cuestiones relativas a los servicios que había que municipalizar, las zonas que debían urbanizarse, cómo organizar la enseñanza pública, cómo contribuir al abaratamiento de las viviendas y las subsistencias, y otros problemas "de índole puramente municipal". Cfr. T. Elorrieta y Artaza, La municipalización de servicios en el Condado de Londres, cit., p. 9. Por su parte, de forma muy elocuente había manifestado Sir William Harcourt que "todos somos ahora socialistas". La cita en E. Reichel, Der Sozialismus der Fabier, cit., pp. 93.

102 En las elecciones locales de 1892, de 118 miembros seis fueron fabianos, uno de ellos el propio Sidney Webb. A. M. MacBriar, Fabian socialism and english politics..., cit., pp. 222 y 223 y E. Reichel, Der So44 zialismus der Fabier, cit., pp. 92 y 93, quien llamaba la atención sobre el hecho de que Webb fuera elegido, precisamente, por un distrito de mayoría netamente conservadora. 
pecto de otras ciudades inglesas, de modo que una vez puesta al día la ciudad en la materia, aparecerían rápidamente las diferencias partidistas, como efectivamente ocurrión ${ }^{103}$.

Por el contrario, ni Firth ni Chamberlain pretendían en modo alguno cambiar la propiedad privada de los medios de producción, sino que creían, simplemente, en la necesidad de la propiedad pública sobre ciertos servicios por motivos de eficiencia, y porque se trataba de monopolios, considerando que esta forma de pensamiento no tenía nada que ver con el socialismo sino con las necesidades vitales de una gran ciudad ${ }^{104}$.

Cuando en los noventa, los fabianos empezaron a exigir la ampliación de la municipalización a otros servicios como la provisión de leche, las panaderías, las casas de empeño o el servicio de incendios, la debilidad de su posición se evidenció, puesto que muchas de sus propuestas fueron rechazadas y la mayoría de los progresistas empezaron a distanciarse. Los fabianos descubrieron que dependían, para lograr que siguieran adelante sus propuestas, del Progressive Party (partido circunscrito al área londinense y de orientación liberal), dado que el laborismo aún no era lo suficientemente fuerte ni se había constituido oficialmente en el Labour Party ${ }^{105}$.

En todo caso y a pesar de un cierto retraso, la ciudad de Londres acabó, pues, por entrar en la dinámica de las municipalizaciones y de la acción pública. Así, se ocupó de la cuestión de las viviendas para obreros (con participación privada), llegando a obtener, en algunos ejercicios, un módico beneficio financiero, además, por supuesto, de disminuir la mortalidad de los barrios reformados y, en general, mejorar el bienestar y la calidad de vida ${ }^{106}$. En 1896 se aprobó la London County Council Act, que autorizaba al Municipio de Londres para ejercer directamente el servicio de tranvías, cosa que hizo a partir de 1899, iniciando la electrificación de las diversas líneas en $1903^{107}$. Asimismo, el LCC asumió el control de las embarcaciones que surcaban el Támesis (Thames steamboats) y de la autoridad portuaria (Port of London Authority) en 1908.

A partir de la segunda década del siglo XX, y sobre todo después de la Primera Guerra Mundial, el interés de los fabianos se desplazó desde el ámbito local al nacional, centrando buena parte de sus estudios y esfuerzos en las nacionalizaciones de servicios.

103 A. M. MacBriar, Fabian socialism and english politics.., cit., p. 194 y 223.

104 A. M. MacBriar, Fabian socialism and english politics..., cit., pp. 195 y 196 Además, Firth desconfiaba de la gestión pública, inclinándose por conceder el monopolio a un contratista particular, eso sí, bajo estrictas condiciones y supervisión pública; no obstante, se mostró en ocasiones indeciso sobre ello. También hubo discrepancias en torno a ciertas demandas laborales que los fabianos apoyaron de forma entusiasta, junto con los laboristas del London County Council, relativas al Municipio como "model employer" (salarios justos, jornada de ocho horas).

105 A. M. MacBriar, Fabian socialism and english politics..., cit., pp. 223 y 224.

106 T. Elorrieta y Artaza, La municipalización de servicios en el Condado de Londres, cit., p. 19.

107 Sobre este tema T. Elorrieta y Artaza, La municipalización de servicios en el Condado de Londres, cit., p. 21 y J. Gascón y Marín, Municipalización de servicios públicos, cit., pp. 177-190. 


\section{LA REACCIÓN POLÍTICA ANGLOSAJONA CONTRA LA MUNICIPALIZACIÓN. LA NATIONAL CIVIC FEDERATION}

A principios del siglo XX las municipalizaciones se habían extendido a lo largo y ancho del territorio inglés, de modo que casi la mitad de las principales aglomeraciones urbanas tenían municipalizados los servicios de gas y agua, unos cuarenta Municipios administraban su propio transporte y aproximadamente sesenta habían promovido la construcción de barrios obreros ${ }^{108}$. Muy posiblemente como reacción ante semejante desarrollo, se desencadenó en Gran Bretaña una fuerte campaña en contra de las municipalizaciones. También en esta ocasión el debate partió de Londres, esta vez con motivo de la renovación del London County Council, prevista para 1907, aunque ya desde finales de los años ochenta el movimiento antimunicipalizador había comenzado a manifestarse.

En efecto, un grupo de hombres de la industria y de las finanzas, que controlaban las tres principales asociaciones industriales londinenses (la Cámara de comercio de Londres, la Industrial Freedom League, y la Society of Arts) capitaneados por sir John Lubbock (lord Avebury, nombre por el que era conocido), presidente de la Asociación de banqueros inglesa y de otras sociedades privadas interesadas en las concesiones de obras públicas, se coaligaron en una violenta campaña contra las municipalizaciones, sirviéndose de todos los instrumentos y medios disponibles: la Cámara de los Lores, el Times y el Daily Mairos.

Este movimiento antimunicipalista, dada la extensión ya adquirida por la municipalización en Inglaterra a principios de siglo, pudo parecer una tentativa extrema y anacrónica para hacer retroceder la difusión de los servicios públicos municipales. Sin embargo, encontró un amplio consenso entre los empresarios, políticos y economistas conservadores y liberales, que se habían movilizado paralelamente al aumento de los partidarios de la municipalización.

La lucha se libró fundamentalmente en el London County Council, instituido en 1889 y en el que, a lo largo de los años noventa, se enfrentaron un bloque compuesto por socialistas (fundamentalmente fabianos) y liberal-radicales y otro bloque integrado por un sector de los conservadores (recordemos que otro sector de los conservadores apoyó, con mayores o menores reservas, algunas de las propuestas reformistas). En torno a estos últimos se coaligaron múltiples intereses, con el objetivo de imponer una mayoría conservadora en las elecciones para renovar el Consejo, previs-

108 P. Dogliani, “Il dibattito sulla municipalizzazione in Europa...”, cit., p. 223. También en P. Dogliani, "La sinistra europea alle origini del movimento...", cit., p. 176.

109 P. Dogliani, “Il dibattito sulla municipalizzazione in Europa...”, cit., p. 222 y P. Dogliani, “La sinistra europea alle origini del movimento...", cit., p. 176. Entre los principales autores contrarios a la idea de toda ingerencia municipal en materia de servicios destacaba no solo a Avebury sino también Walton Clark y el economista Leroy-Beaulieu, este último sosteniendo, incluso, que el servicio de abastecimiento de 46 agua también debía ser particular. Véase por todos D. H. Davis, “The cost of municipal trading”, Society of
Arts (1902: Nov. 21-1903: Nov. 13), pp. 189-203. 
tas para marzo de 1907, e impedir así la transformación en entes públicos del servicio de distribución de agua y de las infraestructuras del puerto, previstas para los años 1902 a $1904^{110}$.

En este sentido, piénsese que el Municipio de Londres constituía una excepción en el panorama de las municipalizaciones y de las administraciones municipales inglesas, puesto que, como apuntamos, llegó bastante tarde a la municipalización de algunos servicios, coincidiendo con la crisis de final de siglo.

La lucha que contrapuso los dos frentes mencionados la testimoniaron los numerosos documentos y materiales puestos a disposición de los electores y de la opinión pública. Los municipalistas crearon en octubre de 1892 la London Reform Union, dirigida por Galton, que tuvo entre sus principales animadores a los Webb y a Shaw. En este sentido, toda la sociedad fabiana se movilizó para la campaña municipalista, reeditando los primeros tratados fabianos y publicando una segunda serie, entre 1898 y 1905, y tratando ampliamente los problemas londinenses: la municipalización de la leche, de los mataderos, de los montes de piedad, de la planificación, los seguros contra incendios, hospitales, red eléctrica, etc. ${ }^{111}$.

Asimismo, se denunciaron algunos monopolios en poder de familias emparentadas con la Corona (el opúsculo Scandal of London Markets revelaba por ejemplo que el principal mercado hortofrutícola de la ciudad, el de Coventgarden, lo controlaba el duque de Betford), e incluso se reivindicó el derecho al voto y la eligibilidad local de las mujeres, mediante una campaña puesta en marcha por Beatrice Webb en 1898. Sin olvidar que ya las Basis fabianas de 1896 exigían la "nacionalización y la municipalización de la industria”, así como el inmediato control municipal del comercio y de algunos géneros de consumo populari12.

Por su parte, los antimunicipalistas respondieron organizando en 1899 un comité propio, el Municipal Trading Committee y una sección de estudio, la London Municipal Society Department of Anti-Socialist Economics, dirigida por W. G. Rowler, que publicó una serie de escritos muy críticos, buscando rebatir las tesis municipalistas de los fabianos y los radicales. Siempre en 1899, al Municipal Trading Committee se añadió una League con el objetivo de organizar la acción contra la municipalización. Todo ello, de forma paralela a una campaña en la prensa (sustancialmente a través de The Times, muchos de cuyos artículos contra la municipalización fueron traducidos y conocidos en otros países europeos) que intentaba convencer a la opinión pública de que las empresas municipalizadas estaban mal administradas, comportaban un incremento de los gastos para los contribuyentes y estaban también sujetas a corrupción política en la asignación de los cargos y puestos administrativos ${ }^{113}$.

110 P. Dogliani, “Il dibattito sulla municipalizzazione in Europa...”, cit., p. 222 y 223.

111 P. Dogliani, “Il dibattito sulla municipalizzazione in Europa...”, cit., pp. 222 y 223.

112 P. Dogliani, “Il dibattito sulla municipalizzazione in Europa...”, cit., p. 224.

113 P. Dogliani, "Il dibattito sulla municipalizzazione in Europa...”, cit., p. 225. 
Los antimunicipalistas también contraatacaron desde los canales institucionales que controlaban. La League, de la cual era portavoz ante la Cámara de los Comunes Avebury, quien presentó un escrito (The danger of municipal trading with particulars of consequent parlamentary action) con el cual se solicitaba que el Parlamento inglés investigase a las empresas municipalizadas, y que en caso de observar una mala gestión, procediese a limitar sus prerrogativas y, en definitiva, la expansión del sector público. El objetivo, más allá de estas peticiones concretas, era claro: el Municipal Trading Committee solicitaba la abrogación de las provisional orders que permitían la municipalización de los servicios del gas y la electricidad, y particularmente el derecho para los Municipios que gestionaban sectores municipalizados de fabricar sus utensilios y maquinaria. Además, insistían especialmente en que la intervención municipal en materia de alojamiento tenía que limitarse al control sanitario y a la clausura de las habitaciones insalubres, sin extenderse a la construcción de viviendas nuevas ${ }^{114}$.

Ante esta situación se constituyó una Comisión parlamentaria de investigación que trabajó entre mayo y julio de 1900, interrumpiendo sus trabajos debido a la crisis política motivada por la guerra anglo-bóer, y los reemprendió de nuevo entre agosto y noviembre. Una vez retomada la investigación parlamentaria, los resultados fueron discutidos en una sesión conjunta entre ambas Cámaras en primavera del año siguiente, que dio lugar a una moción moderadamente antimunicipalista propuesta por Balfour, que imponía una serie de principios generales y un control estatal para autorizar la actuación de empresas industriales municipalizadas ${ }^{115}$.

Esta comisión parlamentaria en materia de municipalización de servicios fue posteriormente profundizada y ampliada por otra investigación realizada por una asociación norteamericana -aunque orientada al conjunto del mundo anglosajón-, la National Civic Federation en 1905.

La National Civic Federation, creada en 1900 con sede en la ciudad de Nueva York, era una asociación constituida por personalidades notables representantes del capital, del trabajo, y de la opinión pública en general. Se fundó con el objetivo de implicar en una acción educativa a las mejores figuras del país y dar vida a un sistema de relaciones industriales que llevase a una superación del conflicto en nombre de la cooperación entre capital y trabajo, así como también fomentar el estudio y las discusiones sobre estas cuestiones por parte de la población, contribuyendo de algún modo a popularizarlas ante la opinión pública, promoviendo, en su caso, una correspondiente actuación de los poderes legislativos al respecto ${ }^{116}$.

Para llevar a cabo su programa, la Federation contaba con una serie de órganos, y además instituía Comisiones para estudiar cuestiones o aspectos socialmente rele-

114 P. Dogliani, "Il dibattito sulla municipalizzazione in Europa...", cit., p. 227.

115 P. Dogliani, "Il dibattito sulla municipalizzazione in Europa...", cit., p. 226.

116 A. Geisser, Fatti ed argomenti intorno alla municipalizzazione, cit., p. 12; P. Dogliani, "Il dibattito

48 sulla municipalizzazione in Europa...”, cit., p. 226. 
vantes en un determinado momento (un Departamento de inmigración; un Departamento industrial y económico, que estudiaba los salarios y el coste de la vida; una Comisión de conciliación, que trataba de las huelgas y los acuerdos contractuales entre empresario y mano de obra). Así, ante la campaña crítica que contra la municipalización se había desencadenado a principios de siglo, la National Civic Federation decidió constituir una Comisión ad hoc que, en septiembre de 1905, recibió el encargo de realizar una investigación sobre la municipalización de servicios que abarcara la situación tanto en Estados Unidos como en Gran Bretaña ${ }^{117}$.

De esta forma, se constituyó una Comisión formada por 150 miembros, reclutados entre personas del mundo universitario y académico, prácticos de la gestión pública, dirigentes de empresas privadas y miembros de organizaciones obreras. La Comisión, a su vez, nombró un Comité ejecutivo de 24 miembros y una Comisión investigadora de 21 miembros, a quien correspondería realizar el trabajo efectivo. Esta última, para garantizar la imparcialidad, se compuso, a su vez, de tres grupos en la misma proporción: defensores de la municipalización, críticos de dicho fenómeno, y personas que, hasta el momento, no habían tomado posición sobre la cuestión ${ }^{118}$.

La Comisión centró su investigación en los cinco sectores municipalizados principales: los tranvías en el Reino Unido (puesto que en Estados Unidos no había ninguna ciudad con tranvías municipales); las conducciones de agua en Estados Unidos (al entender que el número de las mismas en aquel país bastaba -por su cantidad y por su antigüedad- para dar una idea al respecto), y los servicios de gas, iluminación y energía eléctrica, estos tres últimos comparativamente en ambos países. Mediante la investigación se pretendían clarificar y estudiar los siguientes aspectos: las concesiones a empresas privadas, los poderes de control e inspección de las autoridades públicas, la evolución histórica de la municipalización, los efectos de la explotación pública y privada sobre las condiciones políticas y de trabajo, sobre la calidad del servicio y su precio, sobre el coste de producción del servicio, así como sobre la organización directiva, las mejoras del servicio y los resultados financieros ${ }^{119}$.

Los resultados de la investigación de la Comisión fueron publicados en 1907 en tres gruesos volúmenes, y tuvieron notable repercusión en los países industrializados. Las principales conclusiones del informe de la mayoría (hubo también un minority report) fueron las siguientes ${ }^{120}$ :

117 A. Geisser, Fatti ed argomenti intorno alla municipalizzazione, cit., pp. 12 y 13; P. Dogliani, "Il dibattito sulla municipalizzazione in Europa...", cit., p. 227.

118 A. Geisser, Fatti ed argomenti intorno alla municipalizzazione, cit., p. 13; M. Pedregal y Fernández, Municipalización Comparada, cit., pp. 10-12.

119 A. Geisser, Fatti ed argomenti intorno alla municipalizzazione, cit., pp. 12 y 13; P. Dogliani, "Il dibattito sulla municipalizzazione in Europa...", cit., p. 227.

120 E. Ibáñez Papell, Servicios públicos municipales..., cit. pp. 19 y 20; M. Pedregal y Fernández, Municipalización Comparada, cit., p. 12; P. Dogliani, “Il dibattito sulla municipalizzazione in Europa...”,. cit., p. 227. 
a) En primer lugar hay que destacar que la Comisión no formuló ninguna opinión ni adoptó ninguna posición general sobre la explotación pública o privada de servicios, pues se consideró que debía ser resuelta según el criterio del caso por caso, "para cada municipalidad, según las condiciones locales". Es decir, asumió un principio de relatividad en virtud del cual lo que podía ser posible, e incluso positivo, para una localidad podía no serlo para otra.

b) La Comisión admitía tanto la explotación por empresas públicas como por empresas privadas, aunque con dos matizaciones. Por un lado, entendió que todos los servicios relacionados con la higiene y la salud pública debían ser confiados a las administraciones locales. Por el otro, advertía que los servicios públicos, fuesen explotados por empresas públicas o privadas, debían organizarse en régimen de monopolio legal, para obtener mejores resultados.

c) Además, en aquellos casos en que la explotación de los servicios de interés general estuviera sometida a compañías privadas, estas deberían ajustarse a la reglamentación y control de las entidades públicas, con un régimen de reglas y contabilidad uniformes y una publicidad completa.

d) El informe concluía, también, que la buena marcha y el éxito de una empresa municipal dependían del grado de capacidad y de competencia del gobierno local, que las concesiones a compañías privadas debían hacerse a vencimiento fijo, y ser rescatables por un justo precio y que, en definitiva, los Municipios debían tener la posibilidad de explotar directamente sus servicios si así se expresaba mediante el voto popular (referéndum o instrumento similar), sin perjuicio, por supuesto, de una reglamentación pública razonable y adecuada.

En fin, lo cierto es que los resultados obtenidos tanto por la comisión inglesa como por la National Civic Federation contribuyeron, por un lado, a avivar el debate municipalizador en algunos centros y revistas que habían contribuido, precisamente, a difundirlo (como la revista Critica Sociale de Turín, en cuyas páginas se enfrentaron, entre 1908 y 1909, el economista Cabiati y el traductor al italiano de Avebury, Geisser, entonces administrador de la Cassa di Risparmio di Torino y que compartía las preocupaciones del sector inglés antimunicipalista ${ }^{121}$ ) y, por otro lado, a clarificar las posiciones de los municipalistas y los antimunicipalistas, pero también de las corrientes en el seno de los partidarios de la empresa municipal, especialmente entre socialistas y no socialistas ${ }^{122}$. Lo cierto es que, en buena medida como resultado de este intenso debate desarrollado en los primeros años del siglo XX al amparo de los informes mencionados, muchos políticos y operadores económicos se convencieron de que el $\mathrm{Mu}$ nicipal Trading no era sinónimo de socialismo municipal ${ }^{123}$. De este modo, el debate en

121 P. Dogliani, “Il dibattito sulla municipalizzazione in Europa...”, cit., p. 228.

122 P. Dogliani, "Il dibattito sulla municipalizzazione in Europa...”, cit., p. 226.

123 P. Dogliani, “Il dibattito sulla municipalizzazione in Europa...”, cit., pp. 226 y 234. Así por ejemplo, la investigación anglo-americana había puesto de relieve que las clases dirigentes locales inglesas que 
torno a la municipalización de servicios inauguró la segunda década del siglo XX como un debate de carácter fundamentalmente técnico, alejado ya de las connotaciones ideológicas tan discutidas en sus orígenes.

\section{BIBLIOGRAFÍA}

Albi Cholbi, F. (1960): Tratado de los modos de gestión de las corporaciones locales, Aguilar, Madrid.

Avebury (1912): Municipalización y nacionalización de los servicios públicos, traducción de la tercera edición inglesa a cargo de J. Pérez Hervás, Imprenta Eugeni Subirana, Barcelona.

Boverat, R. (1912): Le socialisme municipal en Anglaterre et ses résultats financiers, 10 ed., Arthur Rousseau, Paris.

Carro Fernández-Valmayor, J. L. (1994): "La doctrina clásica alemana sobre la personalidad jurídica del Estado. Notas para una relectura”, en AA. VV, Administración instrumental. Libro homenaje al Profesor Clavero Arévalo, Madrid, Civitas, pp. 848-870.

Cole, M. (1973): “Beatrice and Sydney Webb”, en M. Katanka (ed.), Radicals, reformers and Socialists, Fabian biographical Series, Charles Knight Ltd., London, pp. 202-259.

Cuchillo Foix, M. (1987): La reforma del régimen local en Inglaterra y Gales, Instituto de Estudios de Administración Local, Madrid.

Davis, D. H. (1903): “The cost of municipal trading”, Society of Arts, Journal 41 (1902: Nov. 21-1903: Nov. 13), pp. 189-203.

Dogliani, P. (1988): “Il dibattito sulla municipalizzazione in Europa dall'inizio del novecento alla prima guerra mondiale", en A. Berselli / F. della Peruta / A. Varni (a cura di), La municipalizzazione in area padana. Storie ed esperienze a confronto, Franco Angeli, Milano, pp. 220-256.

Dogliani, P. (2003): "La sinistra europea alle origini del movimento comunale internazionale”, en P. Dogliani/ O. Gaspari (a cura di), L'Europa dei comuni dalla fine dell'Ottocento al secondo dopoguerra, Donzelli, Roma, pp. 167-200.

Elorrieta y Artaza, T., (1919): Conferencia de 13 de marzo de 1919: la municipalización de servicios en el Condado de Londres, Imprenta Municipal, Madrid.

García de Enterría, E. (2007): “El servicio público del gas”, en E. García de Enterría, Problemas actuales del régimen local, 3 edición, Thomson-Civitas, Madrid, pp. 71-111.

García de Enterría, E. (2007): Dos estudios sobre la usucapión en el Derecho administrativo, 4 a edición, Civitas, Madrid.

García de Enterría, E. (1955): “La actividad industrial y mercantil de los municipios”, $R A P$ 17, mayo-agosto, pp. 87-138.

habían impulsado la municipalización pertenecían a la well-to-do-class, esto es, a aquella clase social de ciudadanos que tenían una gran experiencia en asuntos empresariales y una fortuna personal más allá de la media, como por otra parte resultaba evidente en casos bien conocidos y ya comentados como el de Birmingham y Chamberlain. 
Gascón y Marín, J. (1904): Municipalización de servicios públicos, Librería General Victoriano Suárez, Madrid.

Geisser, A. (1909): Fatti ed argomenti intorno alla municipalizzazione, Estratto dalla Riforma Sociale, Fasc. 1 Anno XVI, Vol. XX -Gennaio-Febbraio 1909, Società Tipografico-editrice Nazionale, Torino.

Ibáñez Papell, E. (1940): Servicios públicos municipales: organización y aspectos económicos, con un estudio de la municipalización del abastecimiento de leche, Barcelona, Bayer Hnos. y Comp., Barcelona.

Jordana de Pozas, L. (1951): “El problema de los fines de la actividad administrativa”, $R A P$ 4, enero-abril, pp. 11-28.

Kühl, U. (2001): “Einleitung”, enU. Kühl, Der Munizipalsozialismus in Europa/ Le socialisme municipal en Europe, Parischen Historische Studien, Oldenbourg Verlag München, pp. 15-21.

Kühl, U. (2001) “Le débat sur le socialisme municipal en Allemagne avant 1914 et la municisipalisation de l'électricité", en U. Kühl, Der Munizipalsozialismus in Europa/ Le socialisme municipal en Europe, Parischen Historische Studien, Oldenbourg Verlag München, pp. 81-99.

Lanchester, F. (1994): Momenti e figure nel Diritto costituzionale in Italia e in Germania, Giuffrè, Milano.

Lanchester F. (2004): Pensare lo Stato. I giuspubblicisti nell'Italia unitaria, Laterza, Roma-Bari.

Lorcin, J. (2001): “Le socialisme municipal en France. Le cas de Saint-Étienne; modèle ou exception?, en U. Kühl, Der Munizipalsozialismus in Europa/ Le socialise municipal en Europe, Parischen Historische Studien, Oldenbourg Verlag München, pp. 61-78.

Lucarini, F. (2003): “La nascita delle scienze comunali tra Italia ed Europa. L'esempio della municipalizzazione dei servizi pubblici locali (1894-1914)”, en P. Dogliani / P. Gaspari, (a cura di), L'Europa dei comuni dalla fine dell'Ottocento al secondo dopoguerra, Donzelli, Roma, pp. 201-219.

MacBriar, A. M. (1966): Fabian socialism and english politics 1884-1918, Cambridge University Press, Cambridge.

Mackenzie, N. (1917): "Percival Chubb and the founding of the Fabian Society", Victorian Studies, 23:1, otoño, pp. 29-55.

Magaldi, N. (2007): Procura existencial, Estado de Derecho y Estado Social, Universidad del Externado, Serie de teoría jurídica y filosofía del derecho núm. 48, Bogotá.

Martín Rebollo, L. (1975): El proceso de elaboración de la Ley de lo contencioso-administrativo de 13 de septiembre de 1888, Instituto de Estudios Administrativos, Madrid.

Milburn, J. F. (1958): “The Fabian Society and the british labour Party", The Western Political Quarterly, 11: 2, June, pp. 319-339.

Mannori, L. /Sordi, B. (2001), Storia del diritto amministrativo, Editori Laterza, RomaBari.

Muratti, N. (1928): Municipalización de los servicios públicos. Estudio económico, financiero, político, jurídico y social, Librería jurídica, Buenos Aires.

52 Nieto, A. (1996): Los primeros pasos del Estado constitucional, Ariel Derecho, Barcelona. 
Pease, E. (1963): The History of Fabian Society, Frank Cass \& Co, London.

Pedregal y Fernández, M. (1930): Municipalización Comparada, Tipografía de Archivos, Madrid.

Pérez Olea, M. (1956): “La crisis del Régimen local inglés”, REVL, núm. 86, pp. 171-195. Posada, A. (1979): “El Municipio”, en A. Posada, Escritos municipalistas de la vida local, Instituto de Administración Pública, Madrid, pp. 239-258.

Posada, A. (1979): “La ciudad moderna”, en A. Posada, Escritos municipalistas de la vida local, Instituto de Administración Pública, Madrid, pp. 317-409.

Posada, A. (1979): "La democracia y el servicio público en el régimen municipal”, en A. Posada, Escritos municipalistas de la vida local, Instituto de Administración Pública, Madrid, 1979, pp. 197-210.

Reichel, E. (1947): Der Sozialismus der Fabier, Verlag Lambert Schneider, Heidelberg.

Rowe, L. S. (1914): El gobierno de la ciudad y sus problemas (trad. española de Lucila Posada), Librería General Victoriano Suárez, Madrid.

Ruiz Ojeda, A. (2006): La concesión de obra pública, Thomson-Civitas, Cizur Menor, Navarra.

Sandulli, A. (2009), Costruire lo Stato. La scienza del diritto administrativo in Italia (1800-1945), Biblioteca Quaderni Fiorentini per la storia del pensiero giuridico moderno $n^{\circ} 84$, Giuffrè, Milán.

Shaw, A. (1889): "The municipal government in Great Britain”, Political Science Quarterly, vol. 4, n², June 1889, pp. 197-229.

Shaw, G. B. (1896): "What socialism will be like" (lecturer delivered before the Hammersmith Socialist Society at William Morris's Kelmscott House, Hammersmith, 12 July 1896, The Labour Leader, 19 December 1896), en G. B. Shaw, Platform and Pulpit, Rupert Hard-Davis (ed.), London, 1962, pp. 23-31.

Shaw, G. B. (1892): Fabian Tract núm. 41, The Fabian Society: its early history, The fabian Society publications, reprint 1909.

Sordi, B. (2007): “Recent studies of Public Law History in Italia (1992-2005)", en Zeitschrift für Neuere Rechtsgeschichte, pp. 274-276.

Stevenson, J. (1988): "De la filantropía al fabianismo", en AA.VV, Ensayos fabianos sobre el pensamiento socialista, Ministerio de Trabajo y Seguridad Social, Madrid, pp. 25-43.

Waldman, L. (1919): The Great collapse: higher fares or public ownership, New York.

Warren, J. (1923): Municipal Trading, The labour publishing company limited, London.

Willis, T. (2001): "Contributing to a real socialist commonwealth: municipal socialism and health care in Sheffield (1918-1930)", en U. Kühl, Der Munizipalsozialismus in Europa/ Le socialisme municipal en Europe, Parischen Historische Studien, Oldenbourg Verlag München, pp. 101-117.

Zucconi, G. (2003): "Il Municipio, nuevo soggetto urbanistico: la svolta di fine Ottocento”, en P. Dogliani / O. Gaspari, (a cura di), L'Europa dei comuni dalla fine dell'Ottocento al secondo dopoguerra, Donzelli, Roma, pp. 63-75. 
